\title{
20 years of Electronic Commerce Research
}

\author{
Satish Kumar ${ }^{1}$ D $\cdot$ Weng Marc Lim ${ }^{2,3} \cdot$ Nitesh Pandey $^{1} \cdot \mathrm{J}_{\text {. Christopher Westland }}^{4}$ \\ Accepted: 1 February 2021 / Published online: 29 March 2021 \\ (c) The Author(s), under exclusive licence to Springer Science+Business Media, LLC part of Springer Nature 2021
}

\begin{abstract}
2021 marks the 20th anniversary of the founding of Electronic Commerce Research $(E C R)$. The journal has changed substantially over its life, reflecting the wider changes in the tools and commercial focus of electronic commerce. ECR's early focus was telecommunications and electronic commerce. After reorganization and new editorship in 2014, that focus expanded to embrace emerging tools, business models, and applications in electronic commerce, with an emphasis on the innovations and the vibrant growth of electronic commerce in Asia. Over this time, ECR's impact and volume of publications have grown rapidly, and $E C R$ is considered one of the premier journals in its discipline. This invited research summarizes the evolution of ECR's research focus over its history.
\end{abstract}

Keywords Electronic commerce research · Bibliometric analysis · Performance analysis $\cdot$ Co-authorship analysis $\cdot$ Bibliographic coupling $\cdot$ Temporal keyword analysis

Satish Kumar

skumar.dms@mnit.ac.in

Weng Marc Lim

lim@wengmarc.com; marclim@swin.edu.au; wlim@swinburne.edu.my

Nitesh Pandey

2018RBM9016@mnit.ac.in

J. Christopher Westland

westland@uic.edu

1 Department of Management Studies, Malaviya National Institute of Technology, Jaipur, Rajasthan 302017, India

2 Swinburne Business School, Swinburne University of Technology, John Street, Hawthorn, Victoria 3122, Australia

3 School of Business, Swinburne University of Technology, Jalan Simpang Tiga, 93350 Kuching, Sarawak, Malaysia

4 Department of Information and Decision Sciences, University of Illinois - Chicago, 601

S. Morgan Street, Chicago, Illinois 60607-7124, USA 


\section{Introduction}

The year 2021 marks the 20th anniversary of the founding of Electronic Commerce Research (ECR). The journal has changed substantially over its life, reflecting the wider changes in the tools and commercial focus of electronic commerce. ECR's early focus was on telecommunications and electronic commerce. After reorganization and new editorship in 2014, that focus expanded to embrace emerging tools, business models, and applications in electronic commerce, with an emphasis on emerging technologies and the vibrant growth of electronic commerce in Asia. Over these years, ECR has steadily improved its stature and impact, as evidenced through various quantitative (e.g., citations, impact factors) and qualitative (e.g., peerinformed journal ranks) measures. According to Clarivate Analytics, ECR's impact factor in 2019 was $2.507,{ }^{1}$ which means that articles published in ECR between 2017 and 2018 received an average of 2.507 citations from journals indexed in Web of Science in 2019. The five-year impact factor of ECR was $2.643,{ }^{1}$ which indicates that articles published in ECR between 2014 and 2018 received an average of 2.643 citations from Web of Science-indexed journals in 2019. According to Scopus, $E C R$ 's CiteScore was $4.3,{ }^{2}$ which implies that articles published in ECR between 2016 and 2019 received an average of 4.3 citations from journals indexed in Scopus in 2019. The source normalized impact per paper (SNIP) of ECR was 1.962, which suggests that the average citations received by articles in the journal is 1.962 times the average citations received by articles in the same subject area of Scopus-indexed journals in 2019. Apart from these quantitative measures, ECR has also been rated highly by peers in the field, as seen through journal quality lists. For example, ECR has been consistently ranked as an "A" journal by the Excellence in Research for Australia (ERA 2010) and the Australian Business Deans Council (ABDC 2013, 2016, 2019) journal ranking lists.

This research presents a 20-year retrospective bibliometric analysis of the evolution of context and focus of ECR's articles [1-5]. To curate a rich bibliometric overview of ECR's scientific achievements, this study explores seven research questions (RQ) which are commonly asked by both authors and our Editorial Board members:

RQ1. What is the trend of publication and citation in ECR?

RQ2. Who are the most prolific contributors (authors, institutions, and countries) in $E C R$ ?

RQ3. What are the most influential publications in ECR?

RQ4. Where have ECR publications been cited the most?

RQ5. What is the trend of collaboration in ECR?

RQ6. Who are the most important constituents of the collaboration network in ECR?

RQ7. What are the major research themes in ECR?

\footnotetext{
1 Web of Science single-year and five-year impact factors for ECR: https://www.springer.com/journal/ 10660.

2 Scopus CiteScore and SNIP for ECR: https://www.scopus.com/sourceid/145669.
} 
A bibliometric analysis can offer a broad, systematic overview of the literature to delineate the evolution of electronic commerce technologies, and point the direction to trending topics and methodologies [5-14]. Our research is organized as follows. Section 2 outlines our bibliometric methodology. Section 3 goes on to performance analysis to uncover contributor and journal performance trends (RQ1-RQ4), the coauthorship analysis performed to unpack collaboration and constituent characteristics (RQ5-RQ6), and the bibliometric coupling and keyword analyses used to reveal the major themes and trends within the ECR corpus (RQ7). Section 4 applies graph theoretic analysis. Section 5 applies cluster analysis. Section 6 applies thematic analysis. Finally, we conclude the study with key takeaways from this retrospective.

\section{Methodology}

Bibliometric methodologies apply graph theoretic and statistical tools for analysis of bibliographic data [15] and include performance analysis and science mapping [16]. To answer research question 1 to research question 4, this study uses performance analysis to measure the output of authors' productivity and impact, with productivity measured using publications per year, and impact measured using citations per year. We begin by measuring the productivity and impact of $E C R$, and then the productivity and impact of authors, institutions, and countries using both publications and citations per year metrics on top of ancillary measures such as citations per publication and $h$-index. Finally, we measure the impact of $E C R$ articles using citations and shed light on prominent publication outlets citing ECR articles.

To answer research question 5 to research question 7, this study uses co-authorship, bibliographic coupling, and keyword analyses. We begin by conducting a coauthorship analysis, which is a network-based analysis that scrutinizes the relationships among journal contributors [17]. Next, we perform bibliographic coupling to obtain the major themes within the ECR corpus. The assumption of bibliographic coupling connotes that two documents would be similar in content if they share similar references $[18,19]$. Using article references, a network was created, wherein shared references were assigned with edge weights and documents were denoted with nodes. The documents were divided into thematic clusters using the Newman and Girvan [20] algorithm. Finally, we track the development of themes throughout different time periods using a temporal keyword analysis. The assumption of this analysis suggest that keywords are representative of the author's intent [21] and thus important for understanding the prominence of themes pursued by authors across different time periods. Indeed, we found that these bibliometric methods complement each other relatively well, as bibliographic coupling was useful to locate general themes while keywords were useful to understand specific topics.

To acquire bibliographic data of ECR articles for the bibliometric analyses mentioned above, this study uses the Scopus database, which is one of the largest academic database that is almost $60 \%$ larger than the Web of Science [21]. Past research has also indicated that the citations presented within the Scopus database correlate more with expert judgement as compared to Google Scholar and Web of Science [22]. We begin by conducting a source search for "Electronic Commerce 
927 articles, reviews, and editorials found after 'source name' search and search in secondary documents for 'Electronic Commerce Research' between 2001 and 2020.

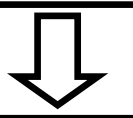

Retrieved all ECR articles from Scopus (516 articles). 411 non-ECR articles were excluded.

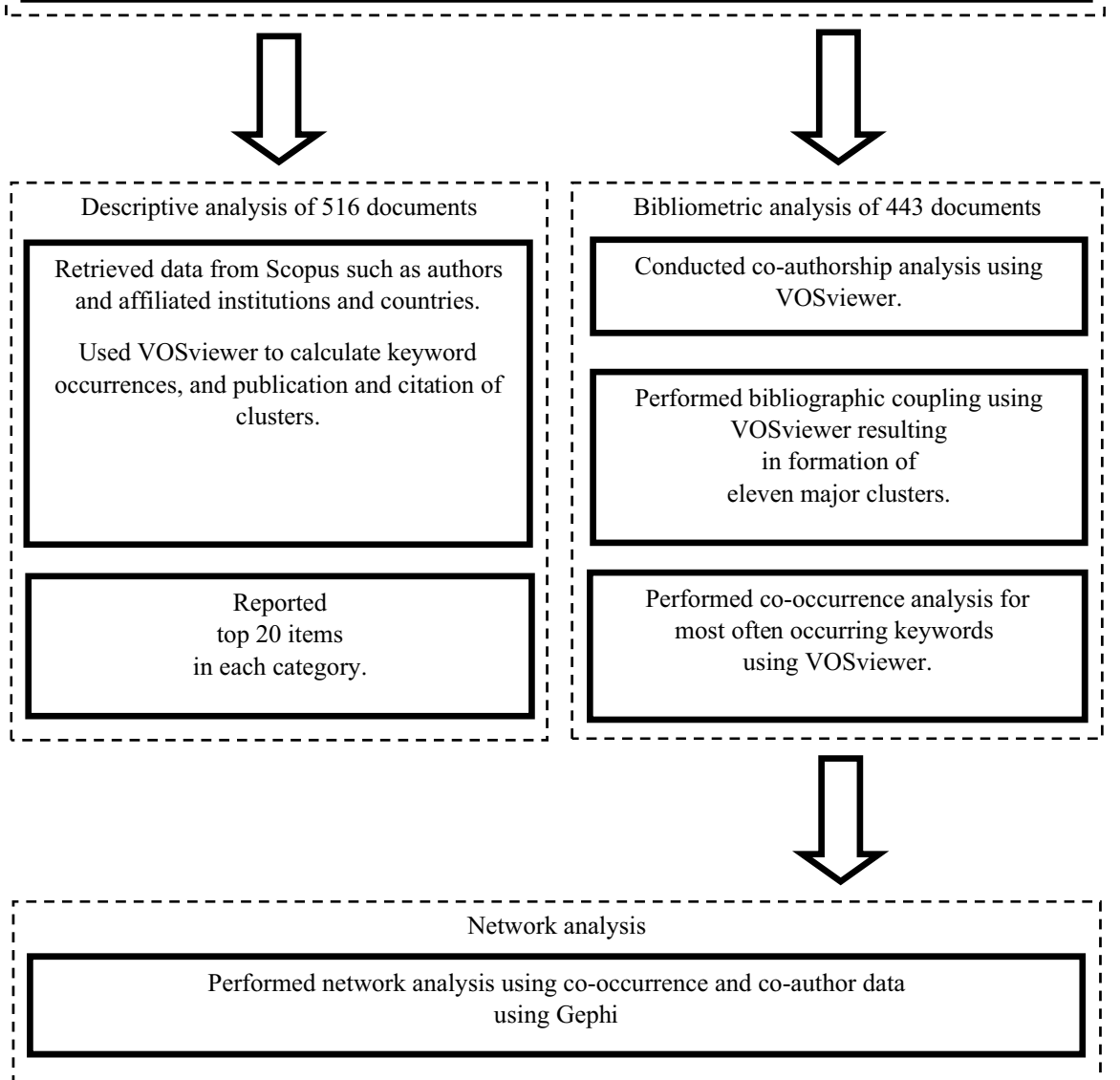

Fig. 1 Research design. Note Bibliometric analysis was conducted for only 443 (primary) documents as 73 (secondary) documents lack full data (affiliation, abstract and keywords)

Research," which resulted in 927 articles, and after filtering out non-ECR articles, we obtain a list of 516 ECR articles (see Fig. 1). However, ECR only gained Scopus indexation in 2005, and thus, only 443 ECR articles (2005-2020) contained full bibliometric data, whereas the remaining 73 ECR articles (2001-2004) contained only partial bibliometric data (e.g., no affiliation, abstract, and keyword entry). All 516 ECR articles were fetched and included in the performance analysis as partial 


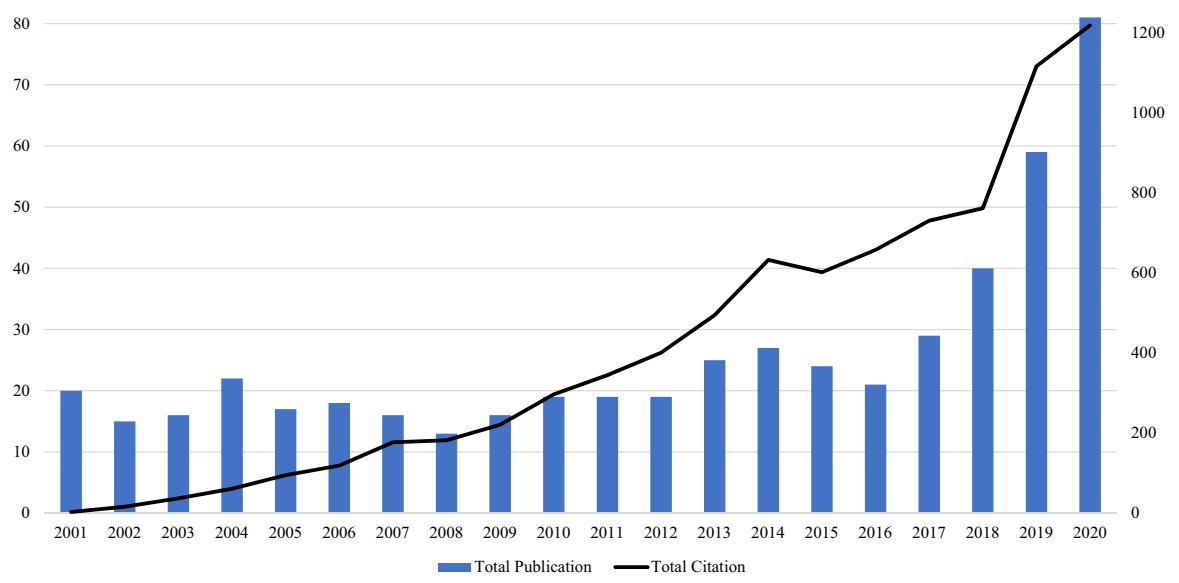

Fig. 2 Annual publication and citation structure of $E C R$

bibliometric data was sufficient, but only 443 ECR articles were included in science mapping (e.g., co-authorship, bibliographic coupling, and keyword analyses using VOSviewer [23] and Gephi [24]) as full bibliometric data was required. This collection of articles met the minimum sample size of 200 articles for bibliometric analysis recommended by Rogers, Szomszor, and Adams [25].

\section{Performance analysis: productivity and impact}

\subsection{ECR}

The publication and citation trends of ECR between 2001 and 2020 are presented in Fig. 2 (RQ1). In terms of publication, the number of articles published in ECR has grown from 20 articles per year in 2001 to 81 articles per year in 2020, with an average annual growth rate of $7.64 \%$. In terms of citations, the number of citations that ECR articles received has grown from three citations in 2001 to 1219 citations in 2020 , with an average annual growth rate of $37.19 \%$. These statistics suggest that $E C R$ 's publications and citations have seen exponential growth since its inception, and that the journal's citations have grown at a much faster rate than its publication, which is very positive.

\subsection{Authors}

The most prolific authors in ECR between 2001 and 2020 are presented in Table 1 (RQ2). The most prolific author is Jian Mou, who has published six articles in ECR, which have garnered a total of 95 citations. This is followed by Yan-Ping Liu and Liyi Zhang, who have published three articles each in $E C R$, which have received a total of 46 and 42 citations, respectively. Among the top 20 contributors, the author with the highest citation average per publication is Katina Michael (TC/TP and TC/ 
Table 1 Most prolific authors for $E C R$ between 2001 and 2020

\begin{tabular}{|c|c|c|c|c|c|c|}
\hline Author & $\mathrm{TP}$ & $\mathrm{TCP}$ & $\mathrm{TC}$ & TC/TP & TC/TCP & $h$ \\
\hline Mou J & 6 & 5 & 95 & 15.83 & 19.00 & 4 \\
\hline Liu Y.-P & 3 & 3 & 46 & 15.33 & 15.33 & 3 \\
\hline Zhang L & 3 & 2 & 42 & 14.00 & 21.00 & 2 \\
\hline $\operatorname{Lin} Z$ & 3 & 3 & 40 & 13.33 & 13.33 & 3 \\
\hline Westland J.C & 3 & 3 & 21 & 7.00 & 7.00 & 3 \\
\hline Luo X & 3 & 1 & 19 & 6.33 & 19.00 & 1 \\
\hline Yan B & 3 & 2 & 6 & 2.00 & 3.00 & 1 \\
\hline Sun J & 3 & 0 & 0 & 0.00 & 0.00 & 0 \\
\hline Michael K & 2 & 2 & 118 & 59.00 & 59.00 & 2 \\
\hline Guo Y & 2 & 2 & 102 & 51.00 & 51.00 & 2 \\
\hline Choo K.-K.R & 2 & 2 & 78 & 39.00 & 39.00 & 2 \\
\hline Khedmatgozar H.R & 2 & 2 & 74 & 37.00 & 37.00 & 2 \\
\hline Wei J & 2 & 2 & 73 & 36.50 & 36.50 & 2 \\
\hline Teng C.-I & 2 & 2 & 71 & 35.50 & 35.50 & 2 \\
\hline Paraschiv C & 2 & 2 & 67 & 33.50 & 33.50 & 2 \\
\hline Chen M.-Y & 2 & 2 & 63 & 31.50 & 31.50 & 2 \\
\hline Cohen J & 2 & 2 & 61 & 30.50 & 30.50 & 2 \\
\hline Maes P & 2 & 2 & 56 & 28.00 & 28.00 & 2 \\
\hline Tsao W.-C & 2 & 2 & 55 & 27.50 & 27.50 & 2 \\
\hline Lee H.S & 2 & 2 & 50 & 25.00 & 25.00 & 2 \\
\hline
\end{tabular}

$\mathrm{TP}=$ total publication(s). $\mathrm{TCP}=$ total cited publication(s). $\mathrm{TC}=$ total citation $(\mathrm{s}) . \mathrm{TC} / \mathrm{TP}=$ cites per publication. $\mathrm{TC} / \mathrm{TCP}=$ cites per cited publication. $h=h$-index

$\mathrm{TCP}=59$ citations), who is followed closely by Yue Guo (TC/TP and TC/TCP $=51$ citations); they are the only two authors who have an average citation greater than 50 for their ECR articles.

\subsection{Institutions}

The most prolific institutions for ECR between 2001 and 2020 are presented in Table 2 (RQ2). IBM, with 14 articles and 371 citations, emerges as the highest contributing institution to ECR. It is surprising yet encouraging to see a high number of contributions coming from practice, which reflects the ECR's receptiveness to publish industry-relevant research. Nonetheless, it is worth mentioning that this contribution is derived from the collective effort of IBM's research labs around the world (e.g., Delhi, Haifa, and New York)—a unique advantage that most higher education institutions do not enjoy unless they have full-fledged research-active international branch campuses around the world. The second and third most contributing institutions are Nanjing University and Xi' an Jiaotong University, with 11 and 10 articles that have been cited 116 and 29 times, respectively. This is yet another interesting observation, as the contributions by 
Table 2 Most prolific institutions for ECR between 2001 and 2020

\begin{tabular}{llllrrr}
\hline Institution & TP & TCP & TC & TC/TP & TC/TCP & $h$ \\
\hline IBM & 14 & 14 & 371 & 26.50 & 26.50 & 9 \\
Nanjing University & 11 & 7 & 116 & 10.55 & 16.57 & 4 \\
Xi'an Jiaotong University & 10 & 7 & 29 & 2.90 & 4.14 & 3 \\
Zhejiang University & 9 & 8 & 85 & 9.44 & 10.63 & 5 \\
Xidian University & 8 & 6 & 56 & 7.00 & 9.33 & 4 \\
Shanghai University & 8 & 2 & 16 & 2.00 & 8.00 & 2 \\
University of California & 7 & 7 & 244 & 34.86 & 34.86 & 7 \\
University of Texas & 7 & 6 & 94 & 13.43 & 15.67 & 4 \\
Wuhan University & 7 & 5 & 68 & 9.71 & 13.60 & 4 \\
Hefei University of Technology & 7 & 2 & 8 & 1.14 & 4.00 & 2 \\
Queensland University of Technology & 6 & 6 & 138 & 23.00 & 23.00 & 4 \\
Tsinghua University & 6 & 4 & 57 & 9.50 & 14.25 & 4 \\
South China University of Technology & 6 & 4 & 44 & 7.33 & 11.00 & 3 \\
Soochow University & 6 & 6 & 40 & 6.67 & 6.67 & 3 \\
University of Illinois & 6 & 6 & 31 & 5.17 & 5.17 & 4 \\
Texas Tech University & 5 & 5 & 131 & 26.20 & 26.20 & 5 \\
University of Wisconsin & 5 & 5 & 99 & 19.80 & 19.80 & 4 \\
Victoria University of Wellington & 5 & 5 & 90 & 18.00 & 18.00 & 4 \\
City University of Hong Kong & 5 & 5 & 54 & 10.80 & 10.80 & 4 \\
University of Alabama & 5 & 5 & 29 & 5.80 & 5.80 & 4 \\
\hline & & 5 & 5 & & & \\
\hline
\end{tabular}

$\mathrm{TP}=$ total publication(s). $\mathrm{TCP}=$ total cited publication(s). $\mathrm{TC}=$ total citation(s). TC/TP=cites per publication. TC/TCP $=$ cites per cited publication. $h=h$-index

Chinese institutions suggest that $E C R$ is a truly international journal despite its origins and operations stemming in the United States. Finally, the University of California ( $\mathrm{TC} / \mathrm{TP}$ and $\mathrm{TC} / \mathrm{TCP}=34.86$ citations) emerges as the institution that averages the most citations per publication, followed by IBM (TC/TP and TC/ $\mathrm{TCP}=26.50$ citations) and Texas Tech University $(\mathrm{TC} / \mathrm{TP}$ and $\mathrm{TC} / \mathrm{TCP}=26.20$ citations).

\subsection{Countries}

The most prolific countries in ECR between 2001 and 2020 are presented in Table 3 (RQ2). China emerges as the most prolific contributor, with 152 articles and 1066 citations. This is followed by the United States, which has contributed 143 articles and 2813 citations. No country other than China and the United States has contributed more than 50 articles to ECR. Nevertheless, it is important to note that $E C R$ also receives contributions from many countries around the world, as the remaining $\pm 50 \%$ of contributions in the top 20 list comes from 18 different countries across Asia, Europe, and Oceania. 
Table 3 Most prolific countries for $E C R$ between 2001 and 2020

\begin{tabular}{|c|c|c|c|c|c|c|}
\hline Country & $\mathrm{TP}$ & $\mathrm{TCP}$ & $\mathrm{TC}$ & $\mathrm{TC} / \mathrm{TP}$ & TC/TCP & $h$ \\
\hline China & 152 & 108 & 1066 & 7.01 & 9.87 & 15 \\
\hline United States & 143 & 133 & 2813 & 19.67 & 21.15 & 23 \\
\hline Taiwan & 35 & 34 & 535 & 15.29 & 15.74 & 12 \\
\hline South Korea & 34 & 26 & 451 & 13.26 & 17.35 & 7 \\
\hline Australia & 30 & 28 & 547 & 18.23 & 19.54 & 13 \\
\hline Germany & 21 & 20 & 565 & 26.90 & 28.25 & 9 \\
\hline United Kingdom & 21 & 18 & 413 & 19.67 & 22.94 & 11 \\
\hline India & 21 & 15 & 163 & 7.76 & 10.87 & 6 \\
\hline Spain & 20 & 18 & 321 & 16.05 & 17.83 & 12 \\
\hline Greece & 17 & 17 & 512 & 30.12 & 30.12 & 11 \\
\hline Hong Kong & 16 & 13 & 142 & 8.88 & 10.92 & 8 \\
\hline Canada & 15 & 12 & 506 & 33.73 & 42.17 & 10 \\
\hline France & 13 & 11 & 218 & 16.77 & 19.82 & 9 \\
\hline Italy & 13 & 11 & 186 & 14.31 & 16.91 & 8 \\
\hline Switzerland & 11 & 11 & 250 & 22.73 & 22.73 & 9 \\
\hline Iran & 11 & 11 & 222 & 20.18 & 20.18 & 7 \\
\hline New Zealand & 10 & 10 & 167 & 16.70 & 16.70 & 8 \\
\hline Japan & 8 & 7 & 87 & 10.88 & 12.43 & 5 \\
\hline Singapore & 7 & 7 & 215 & 30.71 & 30.71 & 5 \\
\hline Sweden & 6 & 6 & 79 & 13.17 & 13.17 & 4 \\
\hline
\end{tabular}

$\mathrm{TP}=$ total publication(s). $\mathrm{TCP}=$ total cited publication(s). $\mathrm{TC}=$ total citation $(\mathrm{s}) . \mathrm{TC} / \mathrm{TP}=$ cites per publication. $\mathrm{TC} / \mathrm{TCP}=$ cites per cited publication. $h=h$-index

\subsection{Articles}

The most cited articles in ECR between 2001 and 2020 are presented in Table 4 (RQ3). The most cited article published in ECR during this period is Füller et al.'s [26] article on the role of virtual communities in new product development $(\mathrm{TC}=270)$. This is followed by Sotiriadis and van Zyl's [27] article on electronic word of mouth and its effects on the tourism industry $(\mathrm{TC}=188)$, Nonnecke et al.'s [28] article on the phenomena of 'lurking' in online communities $(\mathrm{TC}=185)$, Lehdonvirta's [29] article on the factors that drive virtual product purchases $(\mathrm{TC}=170)$, and Bae and Lee's [30] article on the effect of gender on consumer perception of online reviews $(\mathrm{TC}=125)$. The diversity of topics in the most cited articles indicate that electronic commerce is indeed a multi-faceted subject, which we will explore in detail in the later sections. 


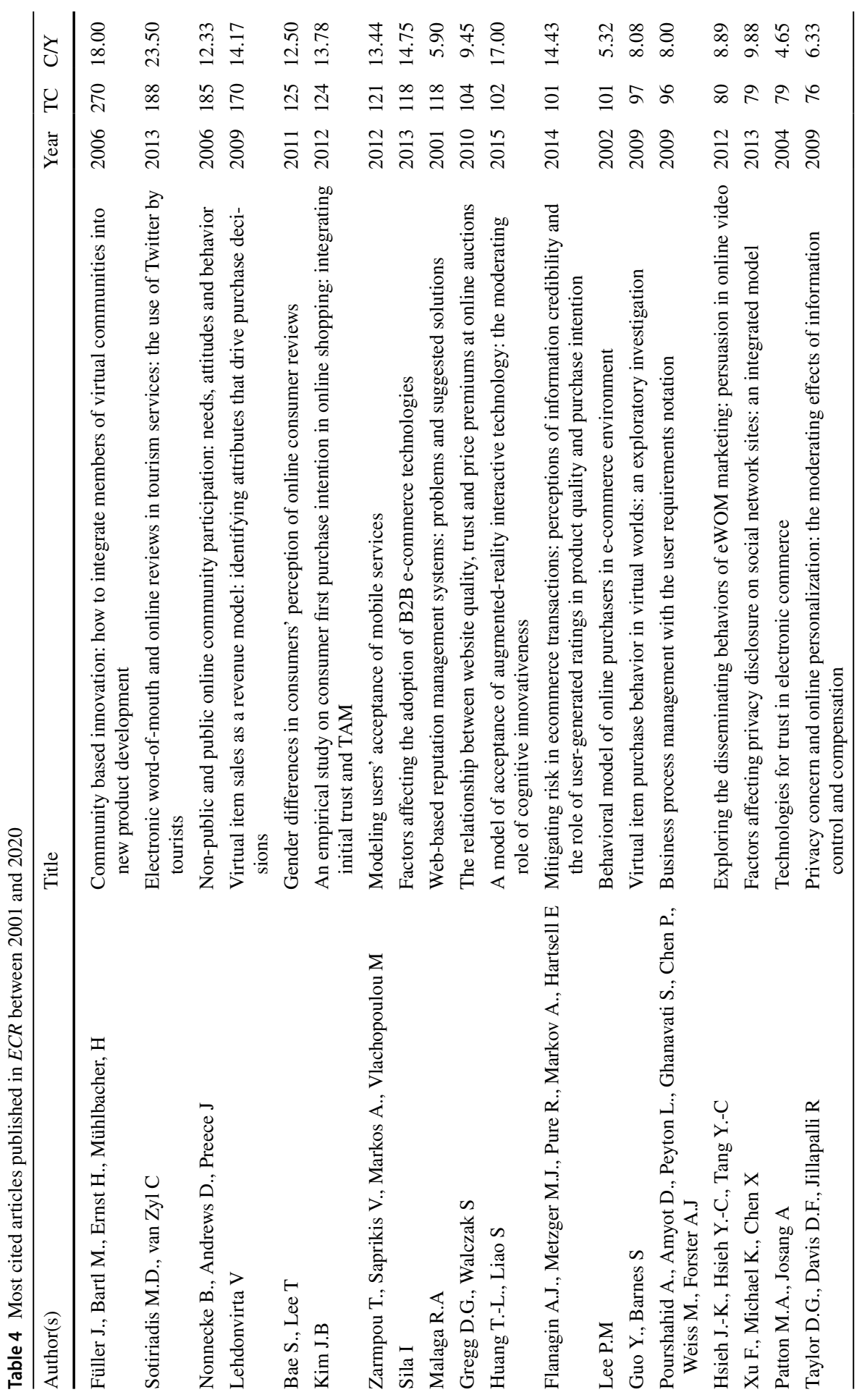




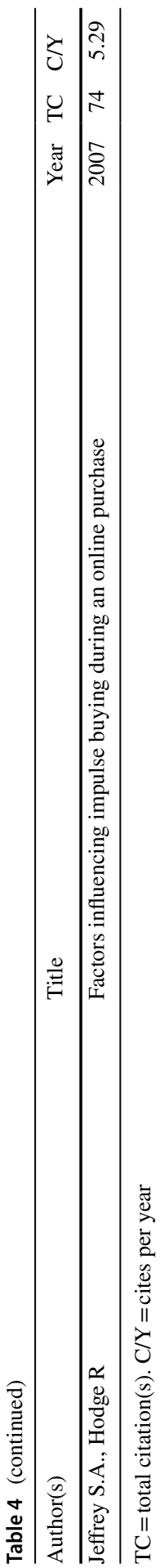

글 Springer 
Table 5 Publications citing ECR the most between 2001 and 2020

\begin{tabular}{|c|c|c|c|c|c|}
\hline tTitle & $\mathrm{TC}$ & $\mathrm{ABDC}$ rank & IF & CiteScore & SNIP \\
\hline Electronic Commerce Research & 267 & A & 2.507 & 4.3 & 1.962 \\
\hline $\begin{array}{l}\text { Lecture Notes in Computer Science including subseries } \\
\text { Lecture Notes in Artificial Intelligence and Lecture } \\
\text { Notes in Bioinformatics }\end{array}$ & 218 & NA & NA & NA & NA \\
\hline Computers in Human Behavior & 95 & A & 5.003 & 12.1 & 3.079 \\
\hline ACM International Conference Proceeding Series & 88 & NA & NA & 0.8 & 0.333 \\
\hline Journal of Retailing and Consumer Services & 69 & A & 4.219 & 7.4 & 2.166 \\
\hline Sustainability & 67 & NA & 2.567 & NA & NA \\
\hline Electronic Commerce Research and Applications & 61 & $\mathrm{C}$ & 3.824 & 6.9 & 1.787 \\
\hline Advances in Intelligent Systems and Computing & 60 & NA & NA & 0.9 & 0.429 \\
\hline Lecture Notes in Business Information Processing & 51 & NA & NA & 1.3 & 0.573 \\
\hline Internet Research & 47 & A & 4.708 & 7.9 & 2.213 \\
\hline Journal of Business Research & 44 & A & 4.874 & 8.9 & 2.76 \\
\hline International Journal of Information Management & 43 & $\mathrm{~A}^{*}$ & 8.21 & 14.1 & 3.773 \\
\hline Decision Support Systems & 43 & $\mathrm{~A}^{*}$ & 4.721 & 9.5 & 2.718 \\
\hline IEEE Access & 41 & NA & 3.745 & 3.9 & 1.734 \\
\hline Information and Management & 38 & $\mathrm{~A}^{*}$ & 5.155 & 11 & 3.002 \\
\hline Communications in Computer and Information Science & 37 & NA & NA & 0.7 & 0.403 \\
\hline Ceur Workshop Proceedings & 31 & NA & NA & 0.6 & 0.293 \\
\hline Journal of Electronic Commerce Research & 30 & B & 1.875 & 4 & 0.963 \\
\hline Industrial Management and Data Systems & 30 & A & 3.329 & 7.9 & 2.502 \\
\hline Telematics and Informatics & 29 & $\mathrm{C}$ & 4.139 & 9.7 & 2.566 \\
\hline Journal of Internet Commerce & 29 & B & NA & 3.7 & 1.203 \\
\hline Expert Systems with Applications & 29 & $\mathrm{C}$ & 5.452 & 11 & 3.139 \\
\hline
\end{tabular}

$\mathrm{TC}=$ total citation(s). ABDC rank=Australian Business Deans Council rank. $\mathrm{IF}=2019$ impact factor by Clarivate Analytics. SNIP = 2019 source normalized impact per paper by Scopus. NA= not available

\subsection{Publication outlets}

The publication outlets that have cited ECR articles the most between 2001 and 2020 are presented in Table 5 (RQ4). The list includes many prestigious journals such as International Journal of Information Management (ABDC $=\mathrm{A}^{*}$, $\mathrm{IF}=8.210)$, Information and Management $\left(\mathrm{ABDC}=\mathrm{A}^{*}, \mathrm{IF}=5.155\right)$, and Decision Support Systems $\left(\mathrm{ABDC}=\mathrm{A}^{*}, \mathrm{IF}=4.721\right)$, among others. The presence of such reputed journals reflects $E C R$ 's own reputation of high standing among its peers. Apart from $E C R$, the publication outlets that have highly cited ECR include Lecture Notes in Computer Science including subseries Lecture Notes in Artificial Intelligence and Lecture Notes in Bioinformatics $(\mathrm{TC}=218)$, Computers in Human Behavior $(\mathrm{TC}=95)$, and ACM International Conference Proceeding Series $(\mathrm{TC}=88)$, which reflect the diversity in publication outlets that $E C R$ is making an impact (e.g., book, conference, journal). 
Table 6 Authors per paper per period

\begin{tabular}{lcclcc}
\hline $\begin{array}{l}\text { Number of } \\
\text { authors }\end{array}$ & $2005-2008(\%)$ & $2009-2012(\%)$ & $2013-2016(\%)$ & $2017-2020(\%)$ & Total (\%) \\
\hline 1 & 10.94 & 17.81 & 12.24 & 8.61 & 11.26 \\
2 & 32.81 & 35.62 & 27.55 & 23.44 & 27.70 \\
3 & 31.25 & 32.88 & 34.69 & 34.45 & 33.78 \\
4 & 20.31 & 5.48 & 14.29 & 19.14 & 15.99 \\
$\geq 5$ & 4.69 & 8.22 & 11.22 & 14.35 & 11.26 \\
\hline
\end{tabular}

\section{Co-authorship analysis: scientific network}

\subsection{Co-authorship}

The co-authorships in ECR between 2005 and 2020 are presented in Table 6 (RQ5). On the one hand, the co-authorship analysis shows that the share of articles written by a single author has gone down over the years from $10.94 \%$ (2005-2008) to $8.61 \%$ (2017-2020). The small and decreasing share of singleauthored articles do not come as a surprise given the importance and proliferation of collaboration to address increasing thematic and methodological complexity in research [31]. On the other hand, the co-authorship analysis shows that multi-authored articles have increased their share in ECR, especially articles with three authors or more. In particular, the share of articles with three and five or more authors have increased from $31.25 \%$ and $4.69 \%$ between 2005 and 2008 to $34.45 \%$ and $14.35 \%$ between 2017 and 2020, respectively. These statistics suggests that collaboration is growing in prominence, which is consistent with recent observations reported by other premier journals in business [32-34], and that $E C R$ is a good home for collaborative research.

\subsection{Network centrality}

The most important authors, institutions, and countries across different measures of centrality are presented in Table 7 (RQ6). In this study, we employ four measures of centrality: degree of centrality, betweenness centrality, closeness centrality, and eigen centrality.

In essence, degree of centrality refers to the number of relational ties a node has in a network. In contrast, betweenness centrality refers to a node's ability to connect otherwise unconnected groups of nodes, wherein nodes act as a gateway for the flow of information. Whereas, closeness centrality refers to a node's closeness to every other node in the network, whereby nodes that reflect a greater number of shortest paths than others in a network indicates the ability of those nodes to transmit information and knowledge across the network with relative ease. Finally, eigen centrality refers to a node's relative importance in a network, whereby nodes that are connected to other highly connected nodes are crucial to information transfer. 


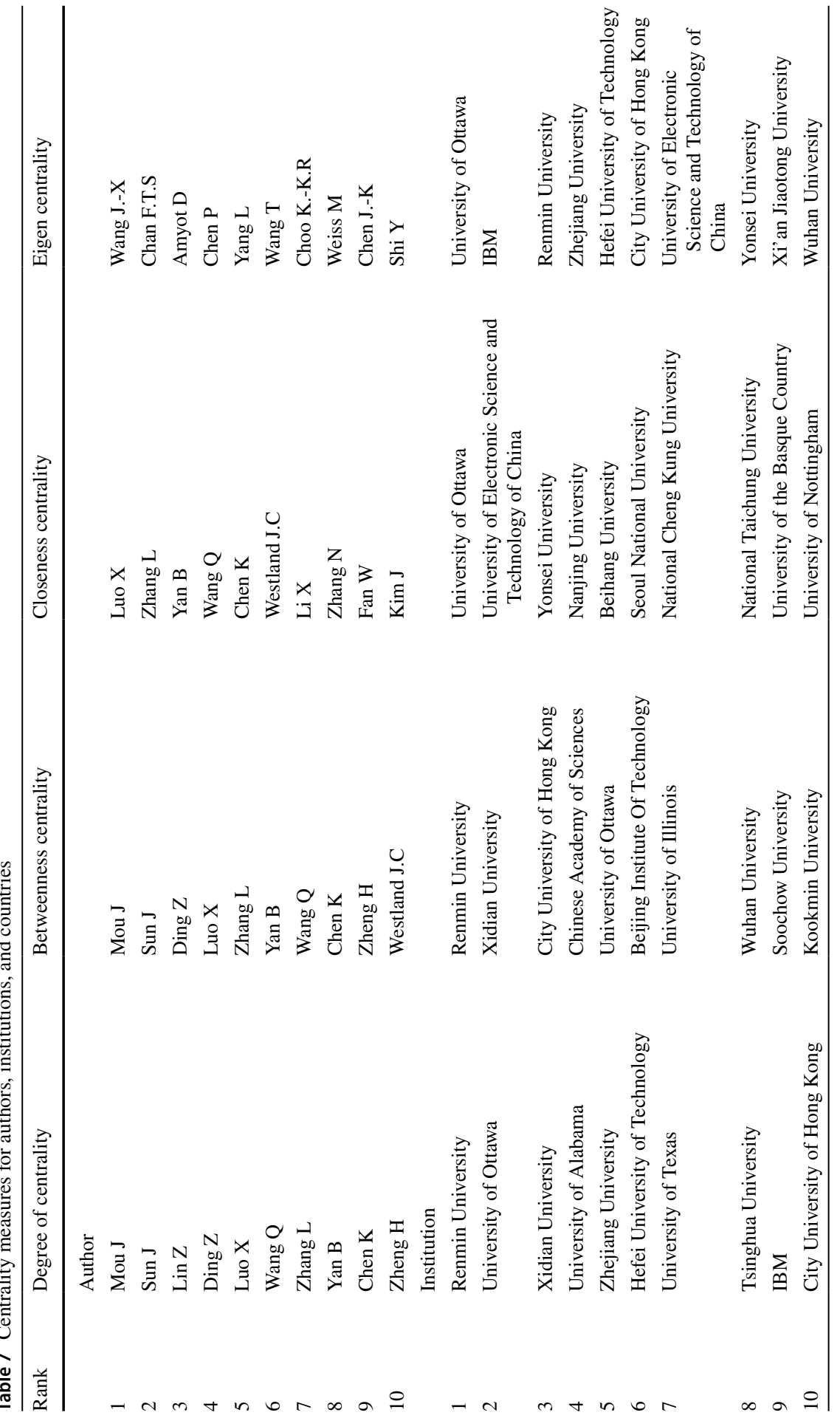




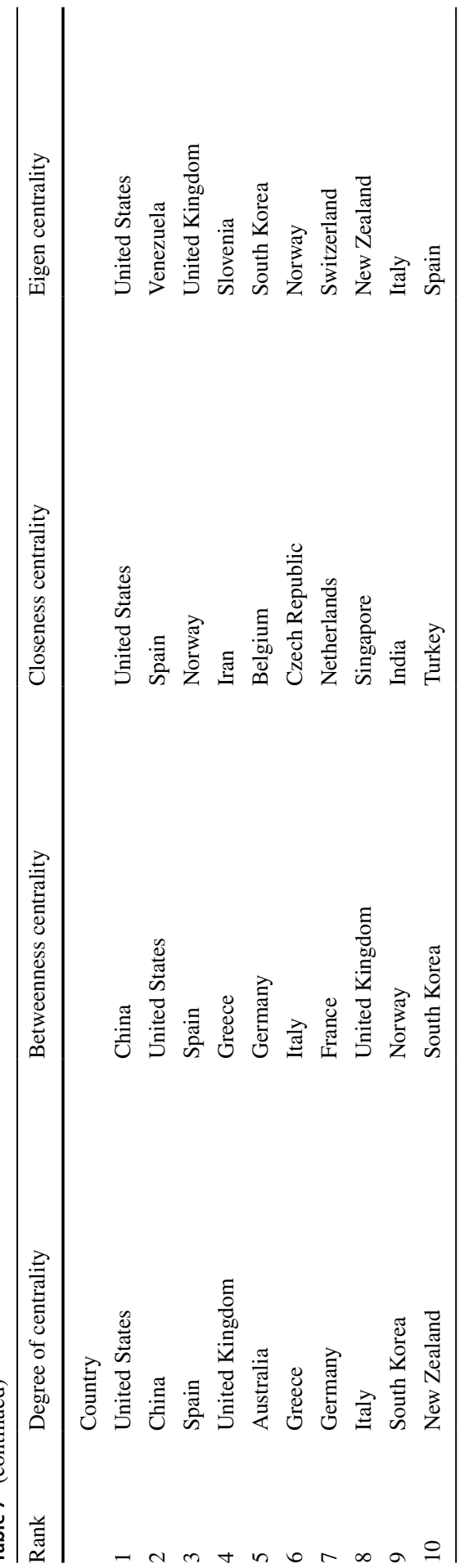




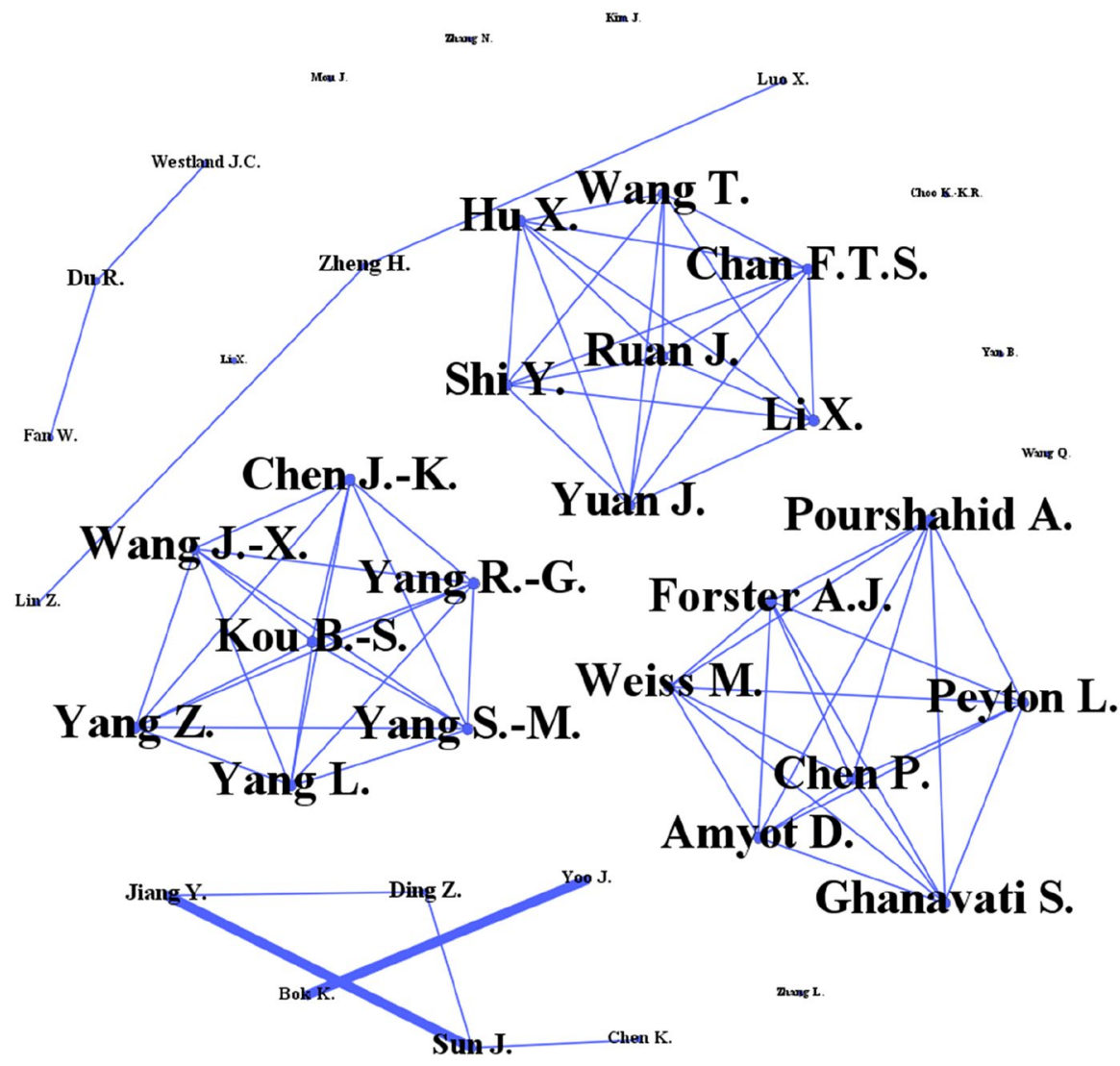

Fig. 3 Author co-authorship network. Note Threshold for inclusion is five or more links in the network

In terms of authors, Jian Mou emerged as the most important author for degree of centrality and betweenness centrality, whereas Xin Luo and Jian-xin Wang were flagged as the most important authors for closeness centrality and eigen centrality, respectively. In terms of institutions, Renmin University emerged as the most important institution for degree centrality and betweenness centrality, whereas the University of Ottawa was rated as the most important institution for closeness centrality and eigen centrality. In terms of countries, China emerged as the most important country for betweenness centrality, whereas the United States emerged as the most important country for the other three measures of centrality. Collectively, these findings indicate the most important constituents for degree of centrality, betweenness centrality, closeness centrality, and eigen centrality in terms of authors, institutions, and countries.

\subsection{Collaboration network}

The author collaboration network in Fig. 3 indicates that authors groups in ECR are fairly separated from each other, especially among highly connected authors (more than 


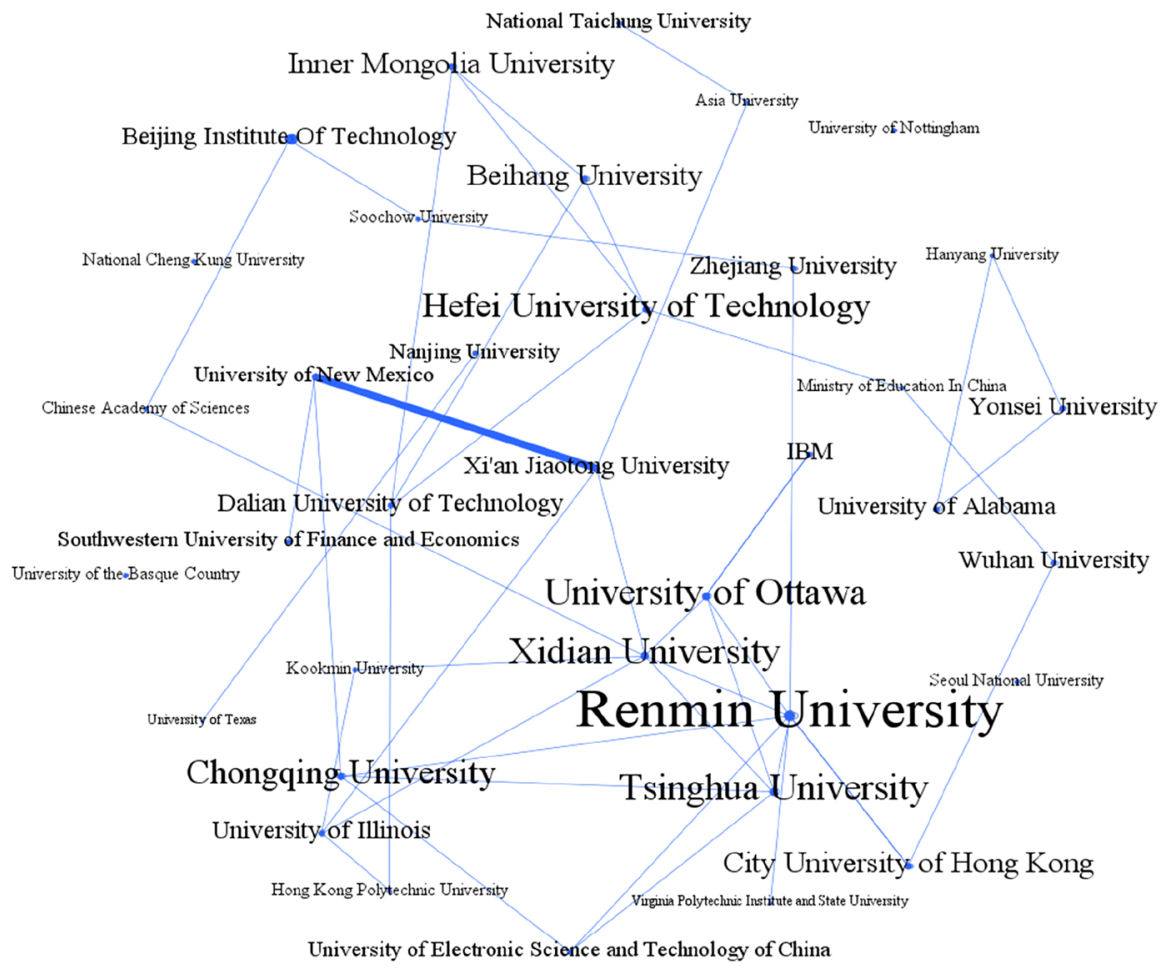

Fig. 4 Institution co-authorship network. Note Threshold for inclusion is five or more links in the network

five links in the network). This suggests that most authors in ECR chose to work in a single team rather than across multiple teams. The institution collaboration network in Fig. 4 reaffirms our earlier finding that Renmin University is indeed the most important constituent of the network, especially among highly connected institutions (more than five links in the network). The institution collaboration network also appears to be more complex than the author collaboration network, wherein institutions appear to be far more connected to each other, indicating a good degree of collaboration across institutional lines. The country network in Fig. 5 presents a similar network scenario, where countries appear to be fairly well connected, with the United States being at the center of the country-level collaboration network. These findings suggest that ECR authors collaborate more actively across institutions and countries than teams.

\section{Bibliographic coupling: thematic clusters}

Bibliographic coupling is applied to unpack the major clusters (themes) within the $E C R$ corpus. The method is predicated on the assumption that documents that share the same references are similar in content $[18,35]$. The application of bibliographic 


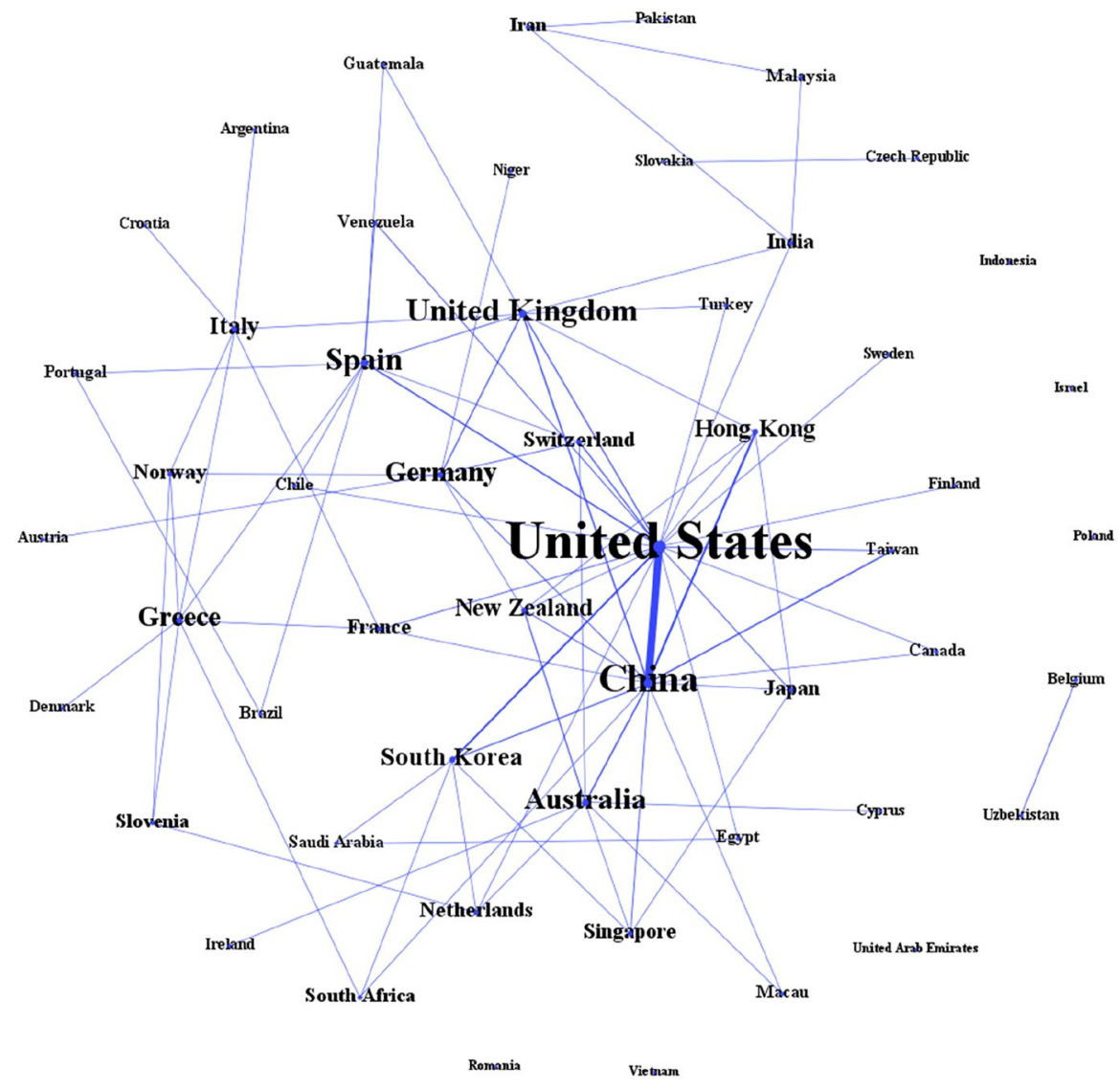

Fig. 5 Country co-authorship network. Note Threshold for inclusion is five or more links in the network

coupling on 443 ECR articles resulted in the formation of 30 clusters, wherein 11 major clusters were identified. The 11 major clusters, which contained 401 (or 90.5\%) ECR articles, were ordered based on number of publications and average publication years, with more recent clusters ordered before older clusters in the case of clusters sharing the same number of publications. The summary of the 11 major clusters, which take center stage in this study, is presented in Table 8.

\subsection{Cluster \#1: online privacy and security}

Cluster \#1 contains 74 articles that have been cited 963 times with an average publication year of 2013.09. The most cited article in this cluster is Zarmpou et al.'s [36] article on the adoption of mobile services. This is followed by Chaudhry et al.'s [37] article on user encryption schemes for e-payment systems, and Antoniou and Batten's [38] article on purchaser's privacy and trust in online transactions. Other articles in this cluster have considered topics such as e-commerce trust models [39], 


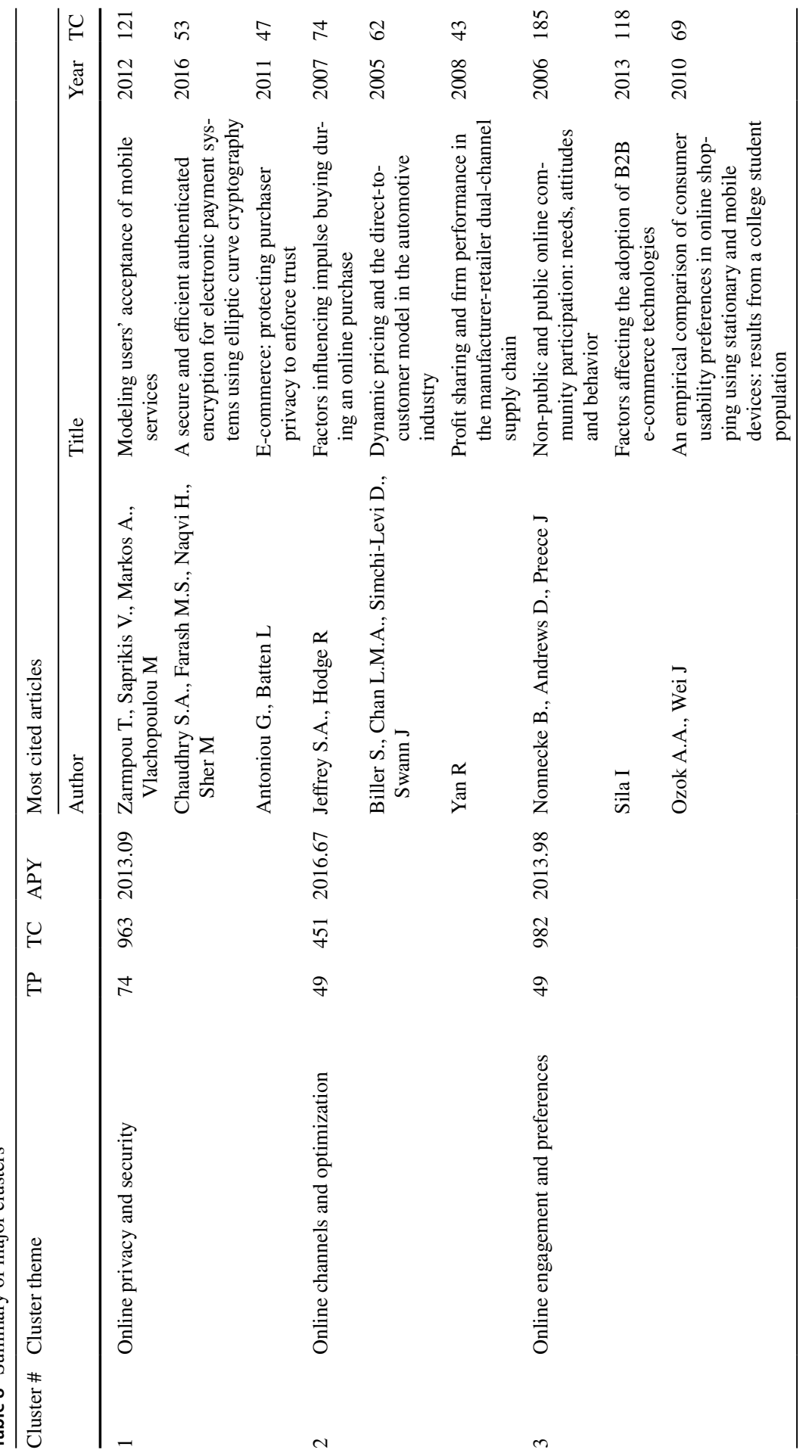




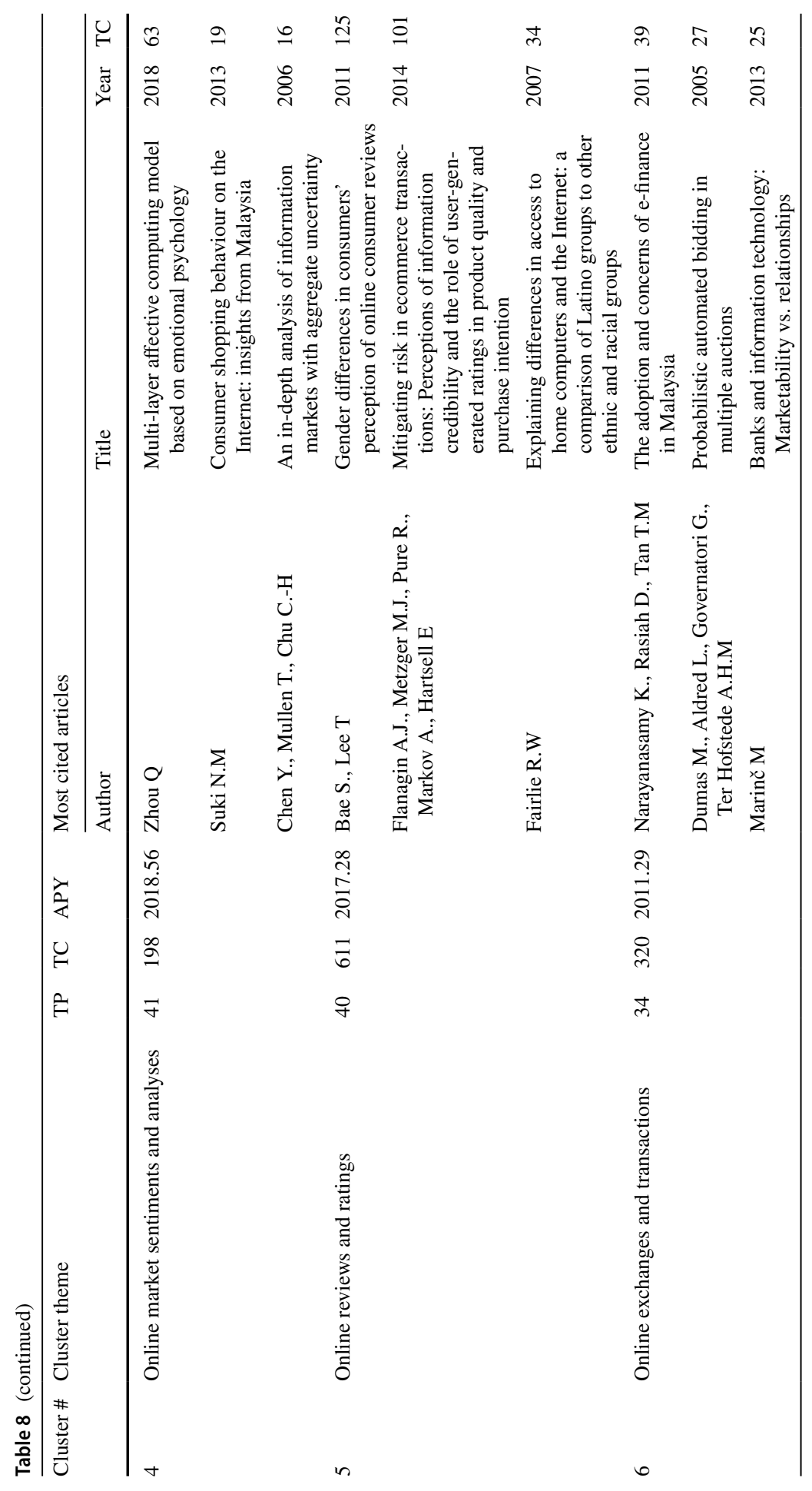




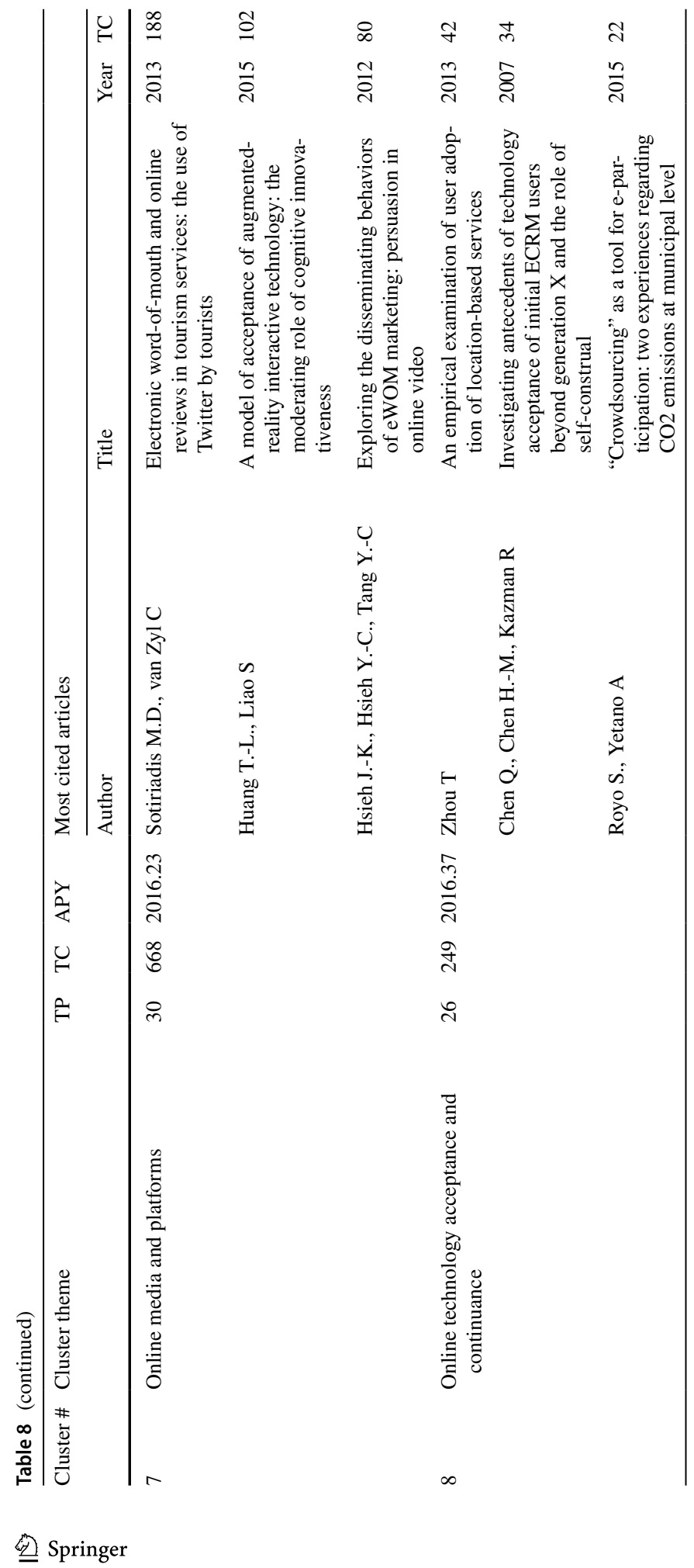




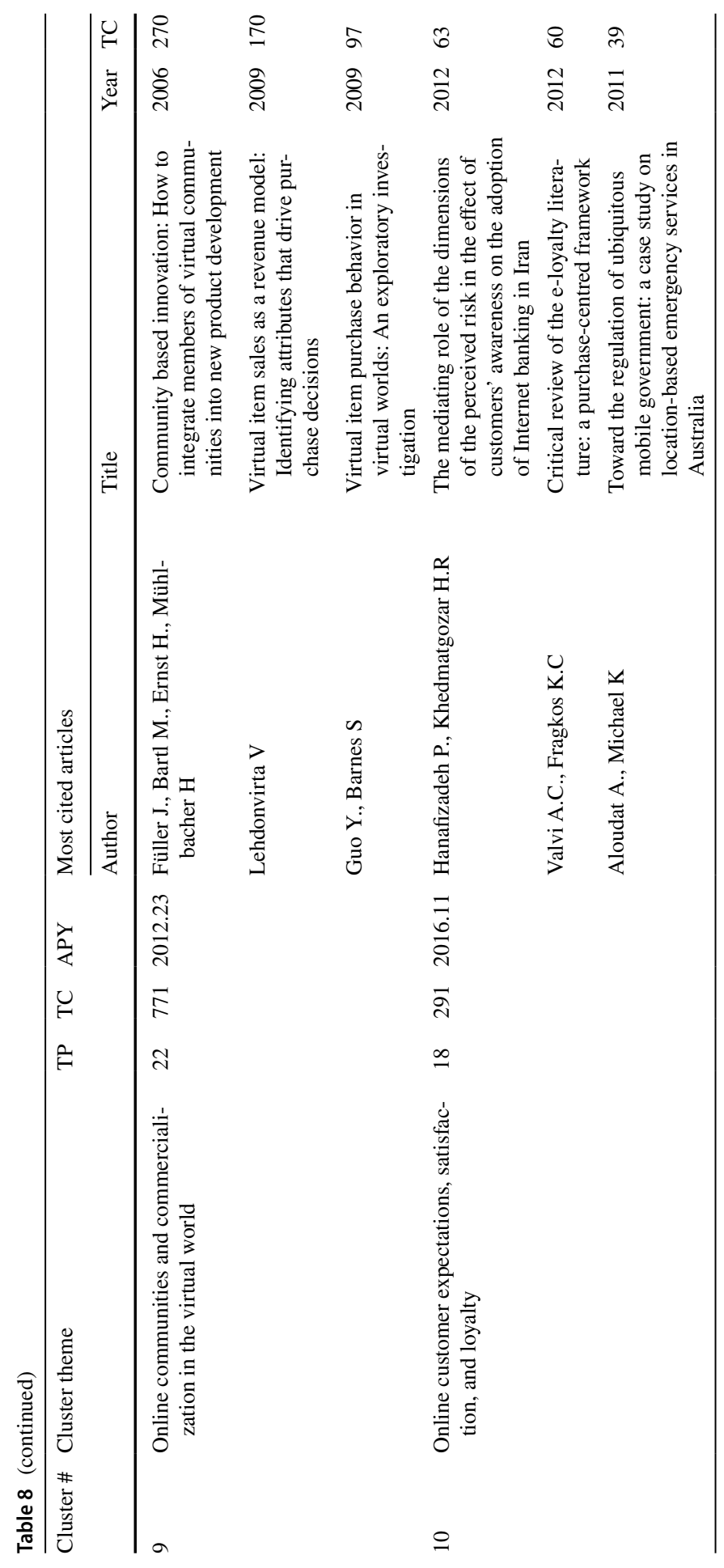




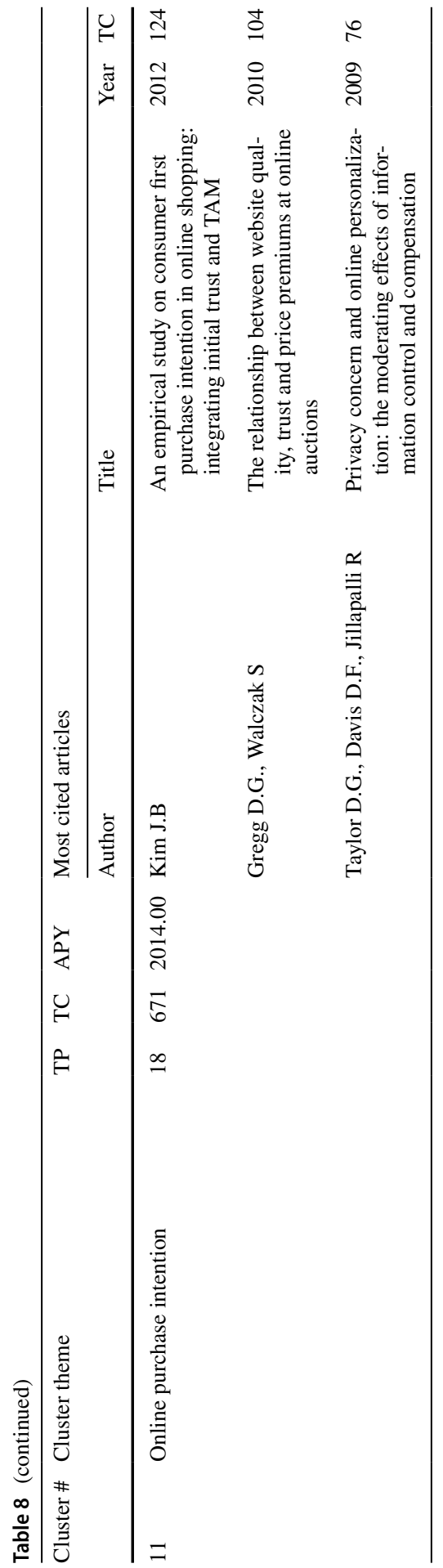


consumer privacy [40], cybercrime and cybersecurity issues [41], gender differences [42], and the development and implementation of various authentication systems $[43,44]$. Thus, ECR articles in this cluster appear to be centered on online privacy and security issues, including equivalent solutions for improved authentication and encryption to improve trust in electronic commerce.

\subsection{Cluster \#2: online channels and optimization}

Cluster \#2 contains 49 articles that have been cited 415 times with an average publication year of 2016.67. The most cited article in this cluster is Jeffrey and Hodge's [45] article on impulse purchases in online shopping. This is followed by Biller et al.'s [46] article on dynamic pricing for online retailing in the automotive industry, and Yan's [47] article on profit sharing and firm performance in manufacturer-retailer dual-channel supply chains. Other articles in this cluster have examined online channels such as peer-to-peer networks and social commerce [48, 49] and optimal supply chain configuration [50, 51]. Thus, ECR articles in this cluster appear to be concentrated on online channels and optimization, particularly in terms of the channel characteristics and price and supply chain optimization in electronic commerce.

\subsection{Cluster \#3: online engagement and preferences}

Cluster \#3 contains 49 articles that have been cited 982 times with an average publication year of 2013.98. The most cited article in this cluster is Nonnecke et al.'s [28] article on online community participation. This is followed by Sila's [52] article on business-to-business electronic commerce technologies, and Ozok and Wei's [53] article on consumer preferences of using mobile and stationary devices. Other articles in this cluster have explored topics such as online community participation and social impact across countries [54], online opinions across regions and its impact on consumer preferences [55, 56], content and context factors [57], data mining techniques [58], and recommender systems and their application in online environments $[59,60]$. Thus, ECR articles in this cluster appear to be focused on online engagement and preferences, including the adoption and usage of technology (e.g., data mining, recommender systems) to curate engagement and shape preferences among target customers in electronic commerce.

\subsection{Cluster \#4: online market sentiments and analyses}

Cluster \#4 contains 41 articles that have been cited 198 times. This cluster has the highest average publication year among the 11 major clusters (2018.56), which indicates that most articles in this cluster are fairly recent. The most cited article in this cluster is Zhou's [61] article on multi-layer affective modeling of emotions in the online environment. This is followed by Suki's [62] article on online consumer shopping insights, and Chen et al.'s [63] article on information markets. Other articles in this cluster have investigated topics such as Internet queries and marketplace 
prediction [64], cross-border electronic commerce using the information systems success model [65], and electronic [66] and social [67] commerce using big data. Thus, ECR articles in this cluster appear to be centered on online market sentiments and analyses, with the use of advanced modeling techniques to unpack fresh insights on electronic commerce being relatively prominent.

\subsection{Cluster \#5: online reviews and ratings}

Cluster \#5 contains 40 articles that have been cited 611 times with an average publication year of 2017.28. The most cited article in this cluster is Bae and Lee's [30] article on online consumer reviews across gender. This is followed by Flanagin et al.'s [68] article on user-generated online ratings, and Fairlie's [69] on the digital divide in online access, which speaks to the technological infrastructure required to post and respond to online reviews and ratings. Other articles in this cluster have examined quantitative and qualitative feedback in online environments [70], electronic word of mouth platforms and persuasiveness [71], online reviews and product innovation [72], recommender systems and product ranking [73], and online rating determinants [74]. Thus, ECR articles in this cluster appear to be concentrated on online reviews and ratings, including its potential differences among consumers coming from different demographic backgrounds.

\subsection{Cluster \#6: online exchanges and transactions}

Cluster \#6 contains 34 articles that have been cited 320 times with an average publication year of 2011.29. The most cited article in this cluster is Narayanasamy et al.'s [75] article on the adoption and concerns of e-finance. This is followed by Dumas et al.'s [76] article on bidding agents in e-auction, and Marinč's [77] article on the impact of information technology on the banking industry. Other articles in this cluster have explored topics such as game theoretic aspects of search auctions [78], auction mechanism for ad space among advertisers [79], trust analysis in online procurement [80], efficiency of reverse auctions [81], and effect of hedonic and utilitarian behaviors on the e-auction behavior [82]. Thus, ECR articles in this cluster appear to be focused on online exchanges and transactions, particularly in terms of auction mechanisms and banking-related services.

\subsection{Cluster \#7: online media and platforms}

Cluster \#7 contains 30 articles that have been cited 668 times with an average publication year of 2016.23. The most cited article in this cluster is Sotiriadis and van Zyl's [27] article on social media in the form of Twitter. This is followed by Huang and Liao's [83] article on augmented reality interactive technology, and Hsieh et al.'s [84] article on online video persuasion in electronic commerce. Other articles in this cluster have investigated topics such as the role of social media in disseminating product information [85], the effect of video formats on person-to-person streaming [86], interpersonal relationship building using social media [87], and microblog 
usage [88]. Thus, ECR articles in this cluster appear to be centered on online media and platforms, particularly in terms of its variation, use, and impact in shaping consumer behavior in electronic commerce.

\subsection{Cluster \#8: online technology acceptance and continuance}

Cluster \#8 contains 26 articles that have been cited 244 times with an average publication year of 2016.37. The most cited article in this cluster is Zhou's [89] article on the adoption of location-based services. This is followed by Chen et al.'s [90] article on the adoption of electronic customer relationship management, and Royo and Yetano's [91] article on crowdsourcing usage in local governments. Other articles in this cluster have examined topics such as gender discrimination in online peerto-peer lending [92], continued usage of e-auction services [93], and investor trust in peer-to-peer lending platforms [94]. Thus, ECR articles in this cluster appear to be concentrated on online technology acceptance and continuance, including determinants and discriminants that explain online technology-mediated behavior across different forms of electronic commerce such as e-auction, e-lending, e-government, and e-customer relationship management.

\subsection{Cluster \#9: online communities and commercialization in the virtual world}

Cluster \#9 contains 22 articles that have been cited 771 times with an average publication year of 2012.23. The most cited article in this cluster is Füller et al.'s [26] article on the role of virtual communities in new product development. This is followed by Lehdonvirta's [29] article on the revenue model of virtual products, and Guo and Barnes's [95] article on the purchase behavior of virtual products. Other articles in this cluster have investigated topics such as metaverse retailing [96], issues faced by developers of virtual worlds [97], the impact of virtual world on e-business models [98], e-commerce transactions in virtual environments [99], and customer value co-creation in virtual environments [26]. Thus, ECR articles in this cluster appear to be focused on the online communities and commercialization in the virtual world, particularly in virtual environments such as online gaming.

\subsection{Cluster \#10: online customer expectations, satisfaction, and loyalty}

Cluster \#10 contains 18 articles that have been cited 291 times with an average publication year of 2016.11. The most cited article in this cluster is Hanafizadeh and Khedmatgozar's [100] article on consumer expectations of risk in online banking. This is followed by Valvi and Fragkos's [101] article on purchase-centered e-loyalty, and Aloudat and Michael's [102] article on regulatory expectations of ubiquitous mobile government. Other articles in this cluster have examined topics such as continued usage of e-services [103], determinants of e-loyalty [104], risk expectations of e-services [105], and e-service quality implications for customer satisfaction and loyalty [106]. Thus, ECR articles in this cluster appear to be centered on online 


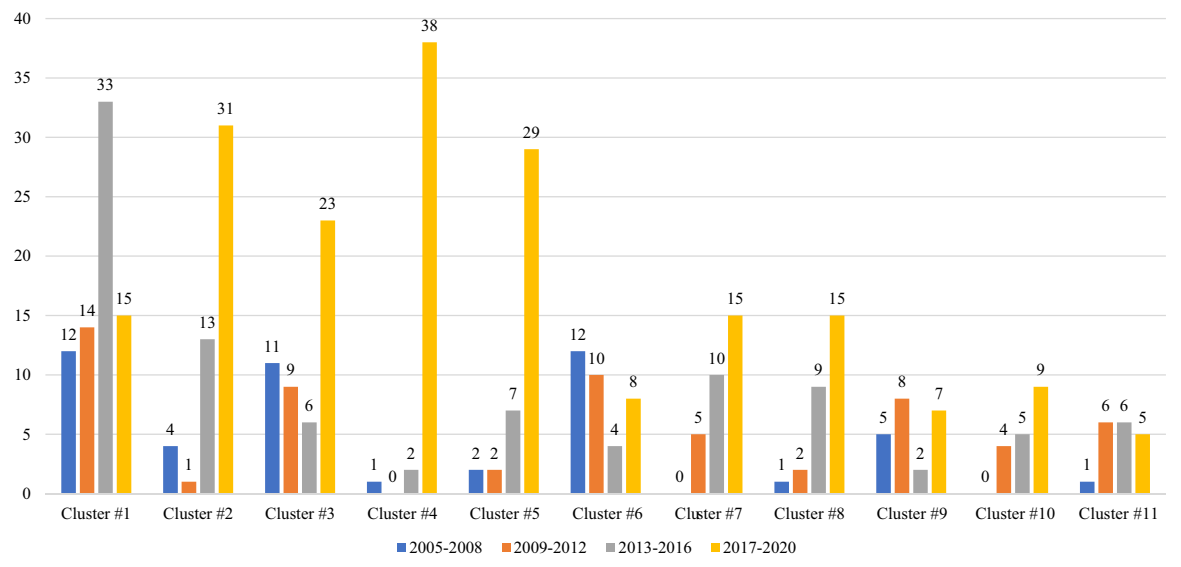

Fig. 6 Period wise publication trend in major clusters. Note Cluster \#1=online privacy and security. Cluster \#2= online channels and optimization. Cluster \#3=online engagement and preferences. Cluster $\# 4=$ online market sentiments and analyses. Cluster $\# 5=$ online reviews and ratings. Cluster $\# 6=$ online exchanges and transactions. Cluster \#7=online media and platforms. Cluster $\# 8=$ online technology acceptance and continuance. Cluster \#9=online communities and commercialization in the virtual world. Cluster $\# 10=$ online customer expectations, satisfaction, and loyalty. Cluster \#11=online purchase intention

customer expectations, satisfaction, and loyalty, particularly in e-service settings such as online banking.

\subsection{Cluster \#11: online purchase intention}

Cluster \#11 contains 18 articles that have been cited 671 times with an average publication year of 2014.00. The most cited article in this cluster is Kim's [107] article on online purchase intention using trust theory and technology acceptance model. This is followed by Gregg and Walczak's [108] article on the effects of website quality on online purchase intention, and Taylor et al.'s [109] article on the effects of privacy concerns on online purchase intention. Other articles in this cluster have explored topics that either reaffirm the findings of the highly cited articles in this cluster, such as privacy concerns and personalization [109, 110], or that extend the breadth of cluster coverage, such as store image [111], risk, and trust [112] as determinants of online purchase intention. Thus, ECR articles in this cluster appear to be concentrated on online purchase intentions, particularly in terms of its multi-faceted determinants that avail or transpire in electronic commerce.

\section{Temporal keyword analysis: thematic evolution}

Building on the thematic clusters uncovered using bibliographic coupling (see Fig. 6), this study performs a temporal keyword analysis to unpack the development of themes and its evolutionary trajectory in ECR over time. 


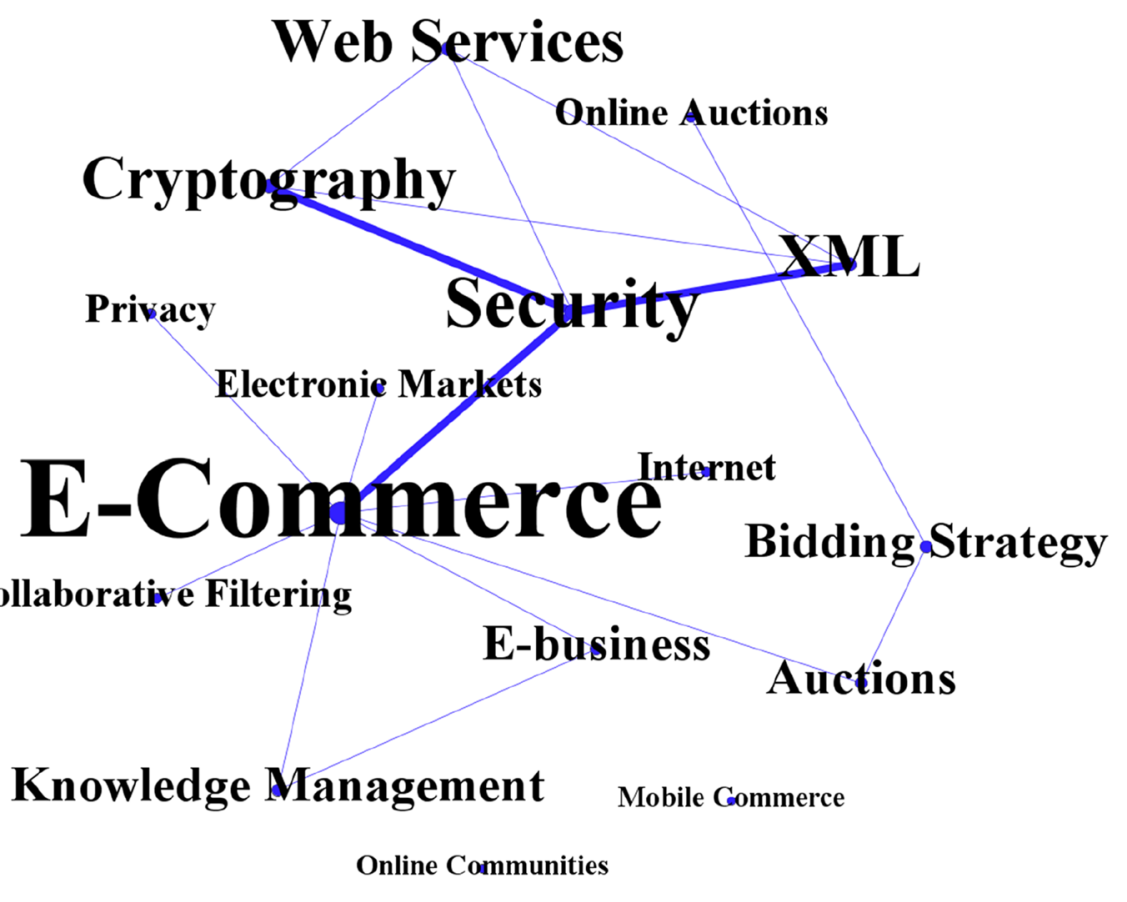

Fig. 7 Keyword network between 2005 and 2008. Note Threshold for inclusion is a minimum of two occurrences

\subsection{Thematic development from 2005 to 2008}

Most ECR articles between 2005 and 2008 appear in Clusters \#1, \#3, and \#6 (see Fig. 6), which indicate research concentration on online privacy and security, online engagement and preferences, and online exchanges and transactions. The keyword network in Fig. 7 confirms this observation. Apart from general keywords such as "e-commerce," keywords such as "cryptography," "privacy," and "security" relate directly to the theme of Cluster \#1, which is about online privacy and security. The prominence of the word "cryptography" indicates the popularity and importance of the topic during this period. Other keywords such as "auctions," "online auctions," and "bidding strategies" relate to the theme of Cluster \#6, which is about online exchanges and transactions, with particular focus on online auction and banking. Other keywords such as "collaborative filtering," "online communities," and "mobile commerce" relate to the theme of Cluster \#3, which is about online engagement and preferences. The bigger and bolder keywords observed in Clusters \#1 and \#3 suggest that the direct benefits and costs of electronic commerce were most pertinent in the early stages of $E C R$, with the augmented aspects of electronic commerce in Cluster \#6 emerging closely behind the two leading clusters in this period. 


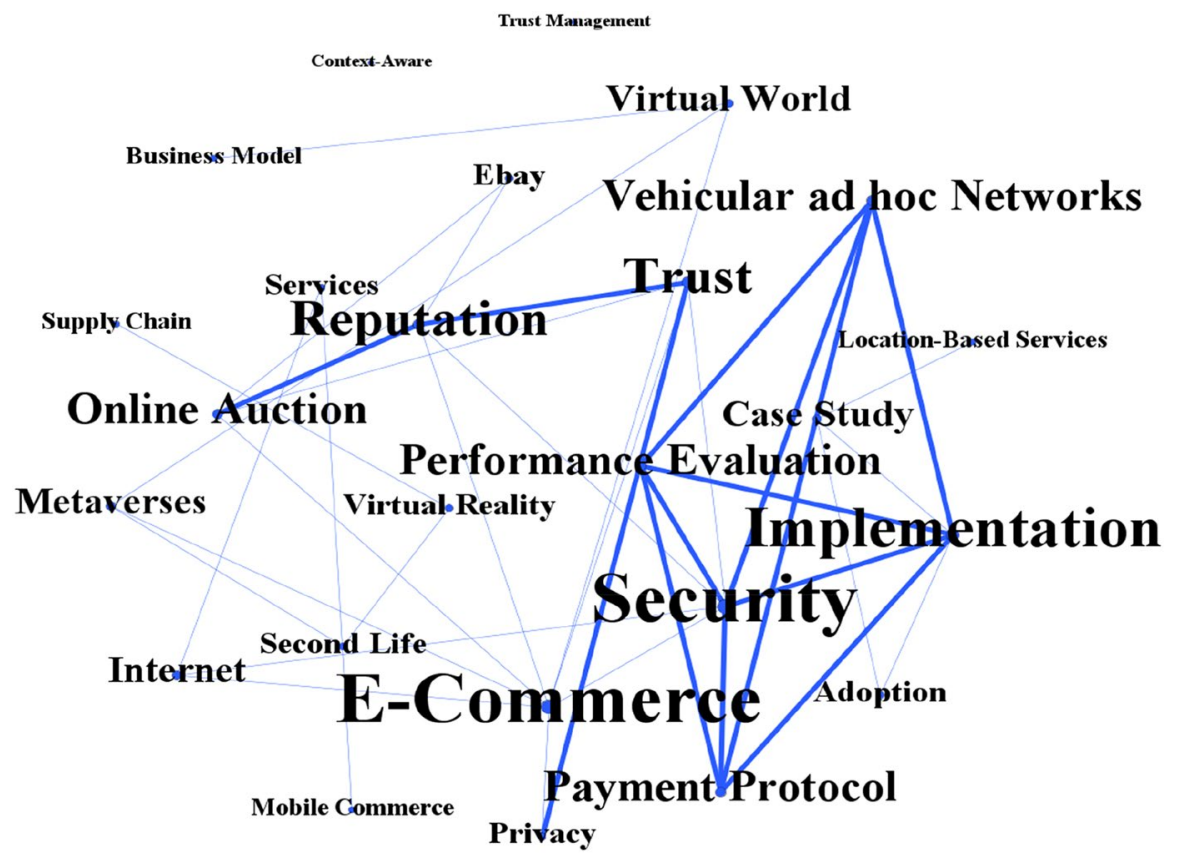

Fig. 8 Keyword network between 2009 and 2012. Note Threshold for inclusion is a minimum of two occurrences

\subsection{Thematic development from 2009 to 2012}

Most ECR articles between 2009 and 2012 are located in Cluster \#1 (see Fig. 6), which reveal the continued pertinence of research concentrating on online privacy and security during this period. Nonetheless, $E C R$ experienced a substantial growth in research focusing on online media and platforms, online communities and commercialization in the virtual world, online customer expectations, satisfaction, and loyalty, and online purchase intention, as seen through ECR articles in Clusters \#7, \#9, \#10, and \#11 during this period. The keyword network in Fig. 8 adds to this observation. In particular, keywords such as "security," "payment protocol," and "trust management" relate to the theme of Cluster \#1 on online privacy and security, whereas keywords such as "metaverses," "second life," "virtual reality," and "virtual world" speak to the emergence of online communities and commercialization in the virtual world characterizing Cluster \#9. Similarly, keywords such as "reputation" and "trust" are important to online customer expectations, satisfaction, and loyalty (Cluster \#10) and their online purchase intention (Cluster \#11). Interestingly, though Cluster \#7 emerged during this period, we did not observe any unique or specific keywords relating to this cluster, which may be attributed to online media and platform research early focus on its "adoption," a keyword that we felt resonates more with Cluster \#8. 
Electronic Word-of-Mouth

Technology Adoption

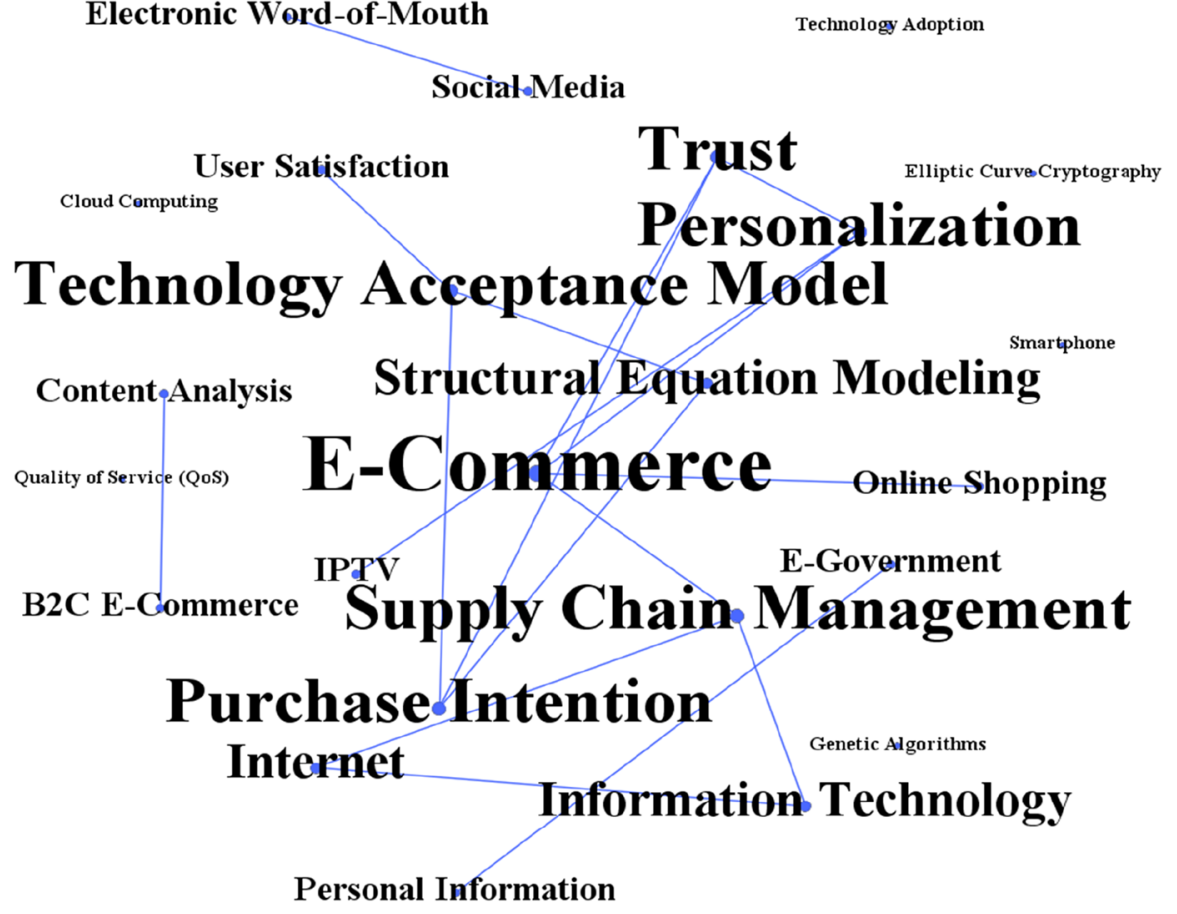

Fig. 9 Keyword network between 2013 and 2016. Note Threshold for inclusion is a minimum of two occurrences

\subsection{Thematic development from 2013 to 2016}

Most ECR articles between 2013 and 2016 continue to be situated in Cluster \#1 (see Fig. 6), which suggest the continued pertinence of research concentrating on online privacy and security during this period. Nonetheless, there are a number of clusters that saw noteworthy growth, such as Clusters \#2, \#5, \#7, \#8, and \#10, which indicate that research attention has also been invested in topics related to online channels and optimization, online reviews and ratings, online media and platforms, online technology acceptance and continuance, and online customer expectations, satisfaction, and loyalty. The keyword network in Fig. 9 supports this observation. More specifically, keywords such as "personal information" and "privacy" indicate continued research in Cluster \#1, though it appears that the focus has shifted from authentication and security mechanisms to privacy matters, which may be attributed to the rise of personalized and targeted online marketing activities (e.g., tracking of user activity for personalized advertisements). Whereas, keywords such as "B2C e-commerce" and "e-government" denote emerging interest in online channels and optimization (Cluster \#2), "electronic 
word of mouth" indicates growing interest in online reviews and ratings (Cluster \#5), "cloud computing," "IPTV," and "social media" reveal increasing interest in online media and platforms (Cluster \#7), "information technology," "technology adoption," and "technology acceptance model" speak to research on online technology acceptance and continuance (Cluster \#8), and "product type," "quality of service," and "user satisfaction" resonate with research on online customer expectations, satisfaction, and loyalty (Cluster \#10).

\subsection{Thematic development from 2017 to 2020}

Most ECR articles between 2017 and 2020 are located in Cluster \#4 (see Fig. 6), which reflect the noteworthy emergence and shift of research concentration from online privacy and security to online market sentiments and analyses. Other thematic clusters such as Clusters \#2, \#3, and \#5 have also witnessed a massive increase in publications during this period. This implies that ECR has become relatively diverse in the research that it publishes, which also explains the rise in the number of papers that the journal publishes during this period. The keyword network in Fig. 10 sheds further light on this observation. In particular, many keywords in the network illustrate a strong research concentration on online market sentiments and analyses, such as "big data," "data mining," machine learning," "sentiment analysis," and "social network analysis" (Cluster \#4). Similarly, keywords such as "dual channel supply chain," "supply chain coordination," and "social commerce" indicate the type of research focusing on online channels and optimization (Cluster \#2), "social influence," "social media," and "social media marketing" reflect research in the area of online engagement and preferences (Cluster \#3), and "consumer reviews," "online reviews," "reputation," and "word of mouth" speak to research on online reviews and ratings (Cluster \#5).

\section{Conclusion}

This study presents a 20-year retrospective of ECR since its inception in 2001. Several research questions were proposed and pursued using a bibliometric methodology consisting of performance analysis and science mapping (e.g., co-authorship analysis, bibliographic coupling, and temporal keyword analysis).

Our first four research questions-i.e., research question 1 to research question 4 - concentrated on the publication and citation trends of ECR. Through performance analysis, we found that ECR has grown exponentially in terms of its publications and citations. Most contributors of ECR come from China and the United States, which reflect (1) China's standing as the world's largest e-commerce market with 50 percent of the world's online transactions occurring in this country, and (2) the United States' standing as the world's pioneer of e-commerce (e.g., Amazon) and her expectation for e-commerce to reach $50 \%$ of total retail sales in the country in 10 years [113]. Interestingly, IBM, a non-academic institution, emerged as the highest contributing institution to the journal, which is unsurprising given that 


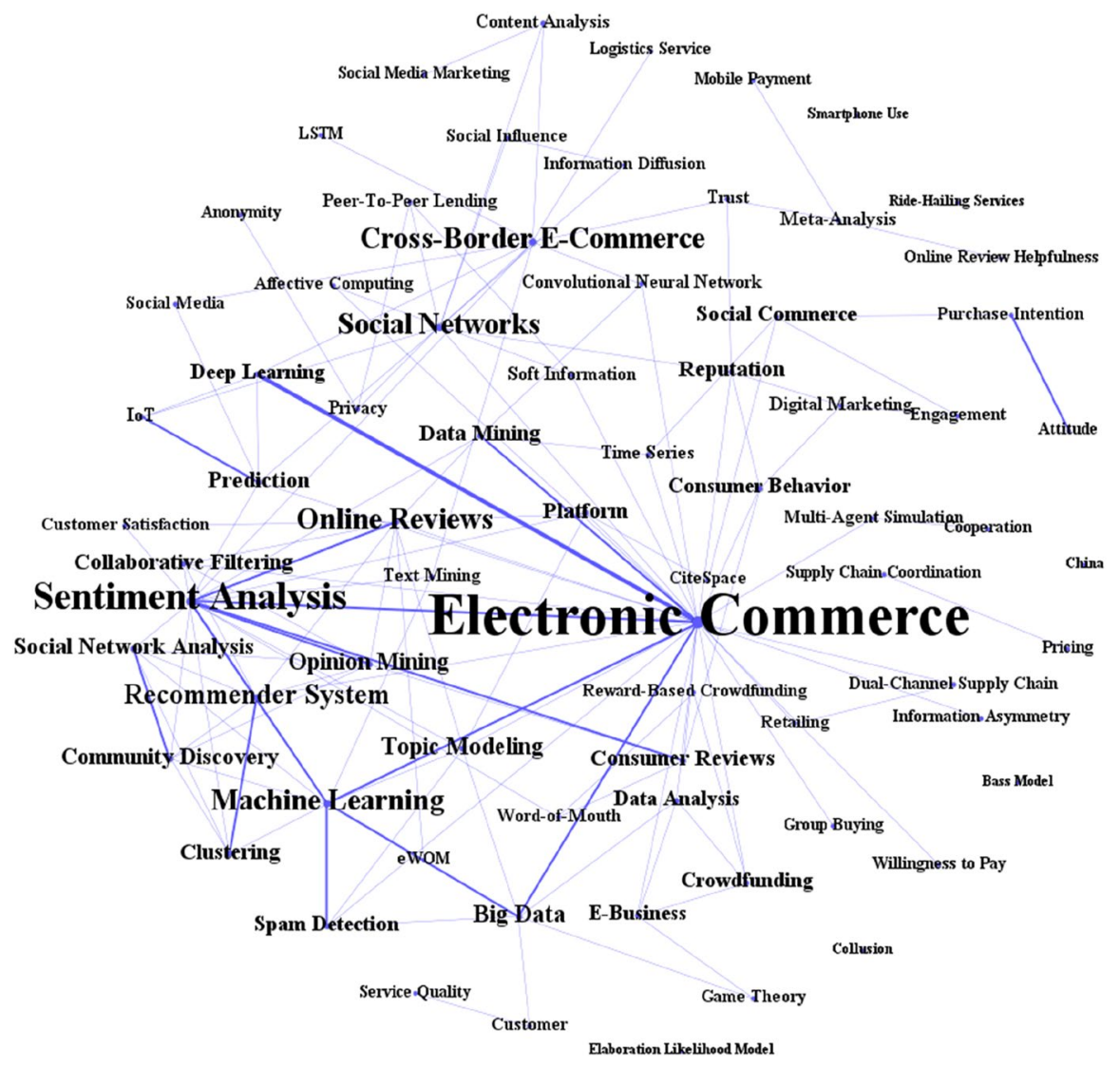

Fig. 10 Keyword network between 2017 and 2020. Note Threshold for inclusion is a minimum of two occurrences

IBM is the largest industrial research organization in the world with 12 research labs across six continents [114]. More importantly, ECR was found to be well received among its peers, with many of its citations coming from prestigious journals in the field of information systems and management. Nevertheless, we observed that ECR receives very little contribution from Africa and several parts of Asia, particularly South Asia and South East Asia. Though electronic commerce may not have been very prominent in these regions in the past, we believe that the coronavirus pandemic that has taken the world by storm in 2020 has accelerated the proliferation and adoption of electronic commerce in these regions, and thus, we would encourage authors from these regions to submit their best papers to ECR in the near future. Thus, we raise two future research questions (FRQs) for exploration:

FRQ1: What are the e-commerce innovations that avail in underexplored regions (e.g., Africa, South Asia, and South East Asia) and how do such innovations fare in terms of similarities and differences in manifestations and impact against their more richly explored counterparts (e.g., China, United States)? 
FRQ2: How can global pandemics such as COVID-19 change or impact e-commerce around the world (e.g., can the pandemic accelerate e-commerce adoption across all layers of society; can the pandemic lead to new innovations; can e-commerce contribute to positive and/or negative economic and social impact during the pandemic — and if yes, what and how, and if no, why)?

Our next two research questions-i.e., research question 5 and research question 6-focused on the collaboration trends in and the important constituents of $E C R$ in the co-authorship network. Using co-authorship analysis, we found that the collaboration culture in $E C R$ has grown with the passage of time, as evidenced through the decreasing share of single-authored articles and the increasing share of multi-authored publications, especially in the five or more authors category. We also observed that the share of multi-authored articles has always been dominant in the journal, with such publications forming nearly $90 \%$ of the corpus at any given point in time. Indeed, these observations reflect the increasing emphasis that universities place on multi-author and inter-/multi-/trans-disciplinary collaborations in promotion and tenure practices and policies [115]. In terms of important constituents in the co-authorship network, Jian Mou emerged as the most important author across two measures of centrality, whereas Renmin University and University of Ottawa emerged as the most important institutions at the institution level, and the United States emerged as the most important constituent at the country level. Nonetheless, we noted that authors who collaborate in ECR do not work much across diverse teams, but they do, however, work a lot across institutions and countries. Future scholars could rely on the centrality networks that we have curated herein this study for potential collaboration with authors from varying institutions and countries who have a good publication record and a research interest to publish with ECR.

Our final research question-i.e., research question 7-was dedicated to unpacking the major themes in ECR. Through bibliographic coupling, our study found 11 major clusters that reflected the major themes underpinning research published in ECR: (1) online privacy and security, (2) online channels and optimization, (3) online engagement and preferences, (4) online market sentiments and analyses, (5) online reviews and ratings, (6) online exchanges and transactions, (7) online media and platforms, (8) online technology acceptance and continuance, (9) online communities and commercialization in the virtual world, (10) online customer expectations, satisfaction, and loyalty, and (11) online purchase intention. Through temporal keyword analysis, our study observed that the topics published in ECR has become more diverse over time, with a noteworthy shift from an early concentration on online privacy and security to a contemporary focus on newer, industry-informed topics, such as online market sentiments and analyses, which we reckon coincides with the emergence of the unique peculiarities of the fourth industrial revolution (IR 4.0), such as big data and machine learning, in recent years [116, 117]. Thus, to extend the line of research that concentrates on unpacking the contemporary realities of e-commerce, we propose another two future research questions (FRQs) for exploration:

FRQ3: How can emergent technologies (e.g., artificial intelligence, big data analytics, blockchain, machine learning) be applied to improve forecasting (e.g., 
cybercrime, social network), optimize functions (e.g., advertising, sales), and protect stakeholders (e.g., privacy, security) in e-commerce?

FRQ4: How can e-commerce operators leverage on emergent technologies to acquire competitive advantages (e.g., how to build trust and good relationships with customers [e.g., digital natives, digital migrants], and how to respond to changes in customer demands and marketplace trends with agility), and whether these competitive advantages that they acquired are sustainable or transient (and if transient, then what can they do to curate, maintain, or replenish their competitive advantages in the long run)?

Though thorough in its approach, this study does suffer from certain limitations. First, this study relies on the Scopus for bibliometric data. Though the database has its merits, as laid out in the methodology section, the bibliographic data is not created for the purpose of bibliometric analysis. This may lead to errors in the data source. Through data cleaning, we have attempted to minimize errors, but any remaining error in the source data, which we might have missed, could have an impact on the final analysis, though we believe that the margin for such errors would be relatively small, if not, negligible. Second, ECR has been around for 20 years, but the dataset available on Scopus, which we used, is only complete for 16 years (2005-2020). Due to this limitation, the science mapping part of the study-i.e., co-authorship, bibliographic coupling, and temporal keyword analysis- had to be restricted to this period only. We do not discount the possibility that the complete set of earlier data (2001-2004) may become available on Scopus in the future, and thus, we would encourage future research aiming to conduct a bibliometric review for $E C R$, perhaps in the next milestone (e.g., 30, 40, or 50 years), to check on such data availability, and if available, to take advantage and conduct a full-fledged science mapping for the journal. Finally, the scientific insights that could be uncovered through a bibliometric methodology, though rich, remain limited. In particular, bibliometric reviews such as ours do not delve into expert information, such as the theories, contexts, and methods employed to create new knowledge on electronic commerce in the ECR corpus. This, in turn, makes it difficult for bibliometric reviews to put forth a comprehensive set of data-informed proposals for future research. Nonetheless, we opine that bibliometric reviews do provide a good starting point of data-informed insights that future research can rely on to understand the trajectory of the extant discussion of electronic commerce in the journal. In particular, we believe that such insights would be useful, not only for future empirical research (e.g., potential collaboration networks, research themes of interest), but also for future reviews on thematic domains in ECR (e.g., systematic reviews on online market sentiments), which can be done in a number of ways, such a critical review [118-120], a thematic review [121, 122], a theory-driven review [123], a method-driven review $[124,125]$, or a framework-based review [126].

\section{Compliance with ethical standards}

Conflict of interest On behalf of all authors, the corresponding author states that there is no conflict of interest. 


\section{References}

1. Schwert, G. W. (1993). The Journal of Financial Economics. A retrospective evaluation (19741991). Journal of Financial Economics, 33(3), 369-424. https://doi.org/10.1016/0304-405x(93) 90012-z.

2. Baker, H. K., Kumar, S., \& Pandey, N. (2021). Thirty years of the Global Finance Journal: A bibliometric analysis. Global Finance Journal, 47, 100492. https://doi.org/10.1016/j.gfj.2019.100492.

3. Merigó, J. M., Pedrycz, W., Weber, R., \& de la Sotta, C. (2018). Fifty years of Information Sciences: A bibliometric overview. Information Sciences, 432, 245-268. https://doi.org/10.1016/j.ins. 2017.11.054.

4. Kumar, S., Marrone, M., Liu, Q., \& Pandey, N. (2020). Twenty years of the International Journal of Accounting Information Systems: A bibliometric analysis. International Journal of Accounting Information Systems, 39, 100488. https://doi.org/10.1016/j.accinf.2020.100488.

5. Donthu, N., Kumar, S., \& Pattnaik, D. (2020). Forty-five years of Journal of Business Research: A bibliometric analysis. Journal of Business Research, 109(1), 1-14. https://doi.org/10.1016/j.jbusr es.2019.10.039.

6. Ellegaard, O., \& Wallin, J. A. (2015). The bibliometric analysis of scholarly production: How great is the impact? Scientometrics, 105(3), 1809-1831. https://doi.org/10.1007/s11192-015-1645-z.

7. Ramos-Rodrígue, A. R., \& Ruíz-Navarro, J. (2004). Changes in the intellectual structure of strategic management research: A bibliometric study of the Strategic Management Journal, 1980-2000. Strategic Management Journal, 25(10), 981-1004. https://doi.org/10.1002/smj.397.

8. Valenzuela, L. M., Merigó, J. M., Johnston, W. J., Nicolas, C., \& Jaramillo, J. F. (2017). Thirty years of the Journal of Business and Industrial Marketing: A bibliometric. Journal of Business and Industrial Marketing, 31(1), 1-17. https://doi.org/10.1108/JBIM-04-2016-0079.

9. Amiguet, L., Gil-lafuente, A. M., Kydland, F. E., \& Merigó, J. M. (2017). One hundred twenty-five years of the Journal of Political Economy : a bibliometric overview. Journal of Political Economy, 1-41. Retrieved from https://www.journals.uchicago.edu/pb-assets/docs/journals/jpe-bib-125.pdf

10. Mulet-Forteza, C., Martorell-Cunill, O., Merigó, J. M., Genovart-Balaguer, J., \& Mauleon-Mendez, E. (2018). Twenty five years of the Journal of Travel and Tourism Marketing: A bibliometric ranking. Journal of Travel and Tourism Marketing, 35(9), 1201-1221. https://doi.org/10.1080/ 10548408.2018.1487368.

11. Baker, H. K., Kumar, S., \& Pandey, N. (2020). A bibliometric analysis of managerial finance: A retrospective. Managerial Finance, 46(11), 1495-1517. https://doi.org/10.1108/MF-06-2019-0277.

12. Donthu, N., Kumar, S., \& Pandey, N. (2020). A retrospective evaluation of Marketing Intelligence and Planning: 1983-2019. Marketing Intelligence and Planning, 39(1), 48-73. https://doi.org/10. 1108/MIP-02-2020-0066.

13. Kumar, S., Spais, G. S., Kumar, D., \& Sureka, R. (2020). A bibliometric history of the Journal of Promotion Management (1992-2019). Journal of Promotion Management, 26(1), 97-120. https:// doi.org/10.1080/10496491.2019.1685622.

14. Kumar, S., Pandey, N., \& Haldar, A. (2020). Twenty years of Public Management Review (PMR): A bibliometric overview. Public Management Review, 22(12), 1876-1896. https://doi.org/10.1080/ 14719037.2020.1721122.

15. Broadus, R. N. (1987). Toward a definition of "bibliometrics." Scientometrics, 12(5-6), 373-379. https://doi.org/10.1007/BF02016680.

16. Cobo, M. J., López-Herrera, A. G., Herrera-Viedma, E., \& Herrera, F. (2011). An approach for detecting, quantifying, and visualizing the evolution of a research field: A practical application to the fuzzy sets theory field. Journal of Informetrics, 5(1), 146-166. https://doi.org/10.1016/j.joi. 2010.10.002.

17 Crane, D. (1969). Social structure in a group of scientists: A test of the invisible college. American Sociological Review, 34(3), 335-352.

18. Weinberg, B. H. (1974). Bibliographic coupling: A review. Information Storage and Retrieval, 10(5-6), 189-196. https://doi.org/10.1016/0020-0271(74)90058-8.

19. Baker, H. K., Kumar, S., \& Pandey, N. (2020). A bibliometric analysis of European Financial Management's first 25 years. European Financial Management, 26(5), 1224-1260. https://doi.org/ 10.1111/eufm.12286.

20. Newman, M. E. J., \& Girvan, M. (2004). Finding and evaluating community structure in networks. Physical Review E, 69(2), 26113. https://doi.org/10.1103/PhysRevE.69.026113. 
21. Comerio, N., \& Strozzi, F. (2019). Tourism and its economic impact: A literature review using bibliometric tools. Tourism Economics, 25(1), 109-131. https://doi.org/10.1177/1354816618793762.

22. Li, J., Sanderson, M., Willett, P., Norris, M., \& Oppenheim, C. (2010). Ranking of library and information science researchers: Comparison of data sources for correlating citation data, and expert judgments. Journal of Informetrics, 4(4), 554-563. https://doi.org/10.1016/j.joi.2010.06. 005 .

23. van Eck, N. J., \& Waltman, L. (2010). Software survey: VOSviewer, a computer program for bibliometric mapping. Scientometrics, 84(2), 523-538. https://doi.org/10.1007/s11192-009-0146-3.

24. Bastian, M., Heymann, S., \& Jacomy, M. (2009). Gephi: An open source software for exploring and manipulating networks. In Proceedings of the Third International ICWSM Conference (2009) (pp. 361-362). https://doi.org/10.1136/qshc.2004.010033.

25. Rogers, G., Szomszor, M., \& Adams, J. (2020). Sample size in bibliometric analysis. Scientometrics, 125, 777-794. https://doi.org/10.1007/s11192-020-03647-7.

26. Füller, J., Bartl, M., Ernst, H., \& Mühlbacher, H. (2006). Community based innovation: How to integrate members of virtual communities into new product development. Electronic Commerce Research, 6(1), 57-73. https://doi.org/10.1007/s10660-006-5988-7.

27. Sotiriadis, M. D., \& van Zyl, C. (2013). Electronic word-of-mouth and online reviews in tourism services: The use of twitter by tourists. Electronic Commerce Research, 13(1), 103-124. https:// doi.org/10.1007/s10660-013-9108-1.

28. Nonnecke, B., Andrews, D., \& Preece, J. (2006). Non-public and public online community participation: Needs, attitudes and behavior. Electronic Commerce Research, 6(1), 7-20. https://doi.org/ 10.1007/s10660-006-5985-x.

29. Lehdonvirta, V. (2009). Virtual item sales as a revenue model: Identifying attributes that drive purchase decisions. Electronic Commerce Research, 9(1-2), 97-113. https://doi.org/10.1007/ s10660-009-9028-2.

30. Bae, S., \& Lee, T. (2011). Gender differences in consumers' perception of online consumer reviews. Electronic Commerce Research, 11(2), 201-214. https://doi.org/10.1007/s10660-010-9072-y.

31. Acedo, F. J., Barroso, C., Casanueva, C., \& Galan, J. L. (2006). Co-authorship in management and organizational studies: An empirical and network analysis. Journal of Management Studies, 43(5), 957-983. https://doi.org/10.1111/j.1467-6486.2006.00625.x.

32. Baker, H. K., Kumar, S., \& Pandey, N. (2020). Thirty years of Small Business Economics: A bibliometric overview. Small Business Economics, 56, 487-517. https://doi.org/10.1007/ s11187-020-00342-y.

33. Burton, B., Kumar, S., \& Pandey, N. (2020). Twenty-five years of The European Journal of Finance (EJF): A retrospective analysis. The European Journal of Finance, 26(1), 1817-1841. https://doi.org/10.1080/1351847X.2020.1754873.

34. Andrikopoulos, A., Samitas, A., \& Kostaris, K. (2016). Four decades of the Journal of Econometrics: Coauthorship patterns and networks. Journal of Econometrics, 195(1), 23-32. https://doi.org/ 10.1016/j.jeconom.2016.04.018.

35. Kessler, M. M. (1963). Bibliographic coupling between scientific articles. American Documentation, 14(1), 123-131.

36. Zarmpou, T., Saprikis, V., Markos, A., \& Vlachopoulou, M. (2012). Modeling users' acceptance of mobile services. Electronic Commerce Research, 12(2), 225-248. https://doi.org/10.1007/ s10660-012-9092-x.

37. Chaudhry, S. A., Farash, M. S., Naqvi, H., \& Sher, M. (2016). A secure and efficient authenticated encryption for electronic payment systems using elliptic curve cryptography. Electronic Commerce Research, 16(1), 113-139. https://doi.org/10.1007/s10660-015-9192-5.

38. Antoniou, G., \& Batten, L. (2011). E-commerce: Protecting purchaser privacy to enforce trust. Electronic Commerce Research, 11(4), 421-456. https://doi.org/10.1007/s10660-011-9083-3.

39. Morid, M. A., \& Shajari, M. (2012). An enhanced e-commerce trust model for community based centralized systems. Electronic Commerce Research, 12(4), 409-427. https://doi.org/10.1007/ s10660-012-9099-3.

40. Smith, R., \& Shao, J. (2007). Privacy and e-commerce: A consumer-centric perspective. Electronic Commerce Research, 7(2), 89-116. https://doi.org/10.1007/s10660-007-9002-9.

41. Kshetri, N. (2013). Cybercrime and cyber-security issues associated with China: Some economic and institutional considerations. Electronic Commerce Research, 13(1), 41-69. https://doi.org/10. 1007/s10660-013-9105-4. 
42. Goh, T. T., \& Sun, S. (2014). Exploring gender differences in Islamic mobile banking acceptance. Electronic Commerce Research, 14(4), 435-458. https://doi.org/10.1007/s10660-014-9150-7.

43. Chen, Y., \& Chou, J. S. (2015). ECC-based untraceable authentication for large-scale activetag RFID systems. Electronic Commerce Research, 15(1), 97-120. https://doi.org/10.1007/ s10660-014-9165-0.

44. Isaac, J. T., Zeadally, S., \& Cámara, J. S. (2012). A lightweight secure mobile payment protocol for vehicular ad-hoc networks (VANETs). Electronic Commerce Research, 12(1), 97-123. https://doi. org/10.1007/s10660-011-9086-0.

45. Jeffrey, S. A., \& Hodge, R. (2007). Factors influencing impulse buying during an online purchase. Electronic Commerce Research, 7(3-4), 367-379. https://doi.org/10.1007/s10660-007-9011-8.

46. Biller, S., Chan, L. M. A., Simchi-Levi, D., \& Swann, J. (2005). Dynamic pricing and the direct-tocustomer model in the automotive industry. Electronic Commerce Research, 5(2), 309-334. https:// doi.org/10.1007/s10660-005-6161-4.

47. Yan, R. (2008). Profit sharing and firm performance in the manufacturer-retailer dual-channel supply chain. Electronic Commerce Research, 8(3), 155. https://doi.org/10.1007/s10660-008-9020-2.

48. Cui, Y., Mou, J., \& Liu, Y. (2018). Knowledge mapping of social commerce research: A visual analysis using CiteSpace. Electronic Commerce Research, 18(4), 837-868. https://doi.org/10.1007/ s10660-018-9288-9.

49. Li, S., \& Sun, W. (2016). A mechanism for resource pricing and fairness in peer-to-peer networks. Electronic Commerce Research, 16(4), 425-451. https://doi.org/10.1007/s10660-016-9211-1.

50. Wang, Z. B., Wang, Y. Y., \& Wang, J. C. (2016). Optimal distribution channel strategy for new and remanufactured products. Electronic Commerce Research, 16(2), 269-295. https://doi.org/10.1007/ s10660-016-9225-8.

51. Rofin, T. M., \& Mahanty, B. (2018). Optimal dual-channel supply chain configuration for product categories with different customer preference of online channel. Electronic Commerce Research, 18(3), 507-536. https://doi.org/10.1007/s10660-017-9269-4.

52. Sila, I. (2013). Factors affecting the adoption of B2B e-commerce technologies. Electronic Commerce Research, 13(2), 199-236. https://doi.org/10.1007/s10660-013-9110-7.

53. Ozok, A. A., \& Wei, J. (2010). An empirical comparison of consumer usability preferences in online shopping using stationary and mobile devices: Results from a college student population. Electronic Commerce Research, 10(2), 111-137. https://doi.org/10.1007/s10660-010-9048-y.

54. Grace-Farfaglia, P., Dekkers, A., Sundararajan, B., Peters, L., \& Park, S. H. (2006). Multinational web uses and gratifications: measuring the social impact of online community participation across national boundaries. Electronic Commerce Research, 6(1), 75-101. https://doi.org/10.1007/ s10660-006-5989-6.

55. Chen, K., Jin, J., Zhao, Z., \& Ji, P. (2020). Understanding customer regional differences from online opinions: A hierarchical Bayesian approach. Electronic Commerce Research (in press). https://doi.org/10.1007/s10660-020-09420-5.

56. Ma, Y., Chen, G., \& Wei, Q. (2017). Finding users preferences from large-scale online reviews for personalized recommendation. Electronic Commerce Research, 17(1), 3-29. https://doi.org/10. 1007/s10660-016-9240-9.

57. Yoon, S. H., \& Kim, H. W. (2019). What content and context factors lead to selection of a video clip? The heuristic route perspective. Electronic Commerce Research, 19(3), 603-627. https://doi. org/10.1007/s10660-019-09355-6.

58. Pan, H., \& Zhou, H. (2020). Study on convolutional neural network and its application in data mining and sales forecasting for e-commerce. Electronic Commerce Research, 20(2), 297-320. https:// doi.org/10.1007/s10660-020-09409-0.

59. Pu, P., Chen, L., \& Kumar, P. (2008). Evaluating product search and recommender systems for e-commerce environments. Electronic Commerce Research, 8(1-2), 1-27. https://doi.org/10.1007/ s10660-008-9015-z.

60. Panniello, U., \& Gorgoglione, M. (2012). Incorporating context into recommender systems: An empirical comparison of context-based approaches. Electronic Commerce Research, 12(1), 1-30. https://doi.org/10.1007/s10660-012-9087-7.

61. Zhou, Q. (2018). Multi-layer affective computing model based on emotional psychology. Electronic Commerce Research, 18(1), 109-124. https://doi.org/10.1007/s10660-017-9265-8.

62. Suki, N. M. (2013). Consumer shopping behaviour on the Internet: Insights from Malaysia. Electronic Commerce Research, 13(4), 477-491. https://doi.org/10.1007/s10660-013-9131-2. 
63. Chen, Y., Mullen, T., \& Chu, C. H. (2006). An in-depth analysis of information markets with aggregate uncertainty. Electronic Commerce Research, 6(2), 201-221. https://doi.org/10.1007/ s10660-006-6958-9.

64. Kang, H. G., Bae, K., Shin, J. A., \& Jeon, S. (2020). Will data on internet queries predict the performance in the marketplace: An empirical study on online searches and IPO stock returns. Electronic Commerce Research (in press). https://doi.org/10.1007/s10660-020-09417-0.

65. Cui, Y., Mou, J., Cohen, J., \& Liu, Y. (2019). Understanding information system success model and valence framework in sellers' acceptance of cross-border e-commerce: A sequential multimethod approach. Electronic Commerce Research, 19(4), 885-914. https://doi.org/10.1007/ s10660-019-09331-0.

66. Liu, S., Shao, B., Gao, Y., Hu, S., Li, Y., \& Zhou, W. (2018). Game theoretic approach of a novel decision policy for customers based on big data. Electronic Commerce Research, 18(2), 225-240. https://doi.org/10.1007/s10660-017-9259-6.

67. Tian, X., \& Liu, L. (2017). Does big data mean big knowledge? Integration of big data analysis and conceptual model for social commerce research. Electronic Commerce Research, 17(1), 169-183. https://doi.org/10.1007/s10660-016-9242-7.

68. Flanagin, A. J., Metzger, M. J., Pure, R., Markov, A., \& Hartsell, E. (2014). Mitigating risk in ecommerce transactions: perceptions of information credibility and the role of user-generated ratings in product quality and purchase intention. Electronic Commerce Research, 14(1), 1-23. https://doi.org/10.1007/s10660-014-9139-2.

69. Fairlie, R. W. (2007). Explaining differences in access to home computers and the Internet: A comparison of Latino groups to other ethnic and racial groups. Electronic Commerce Research, 7(3-4), 265-291. https://doi.org/10.1007/s10660-007-9006-5.

70. Gerdes, J., Stringam, B. B., \& Brookshire, R. G. (2008). An integrative approach to assess qualitative and quantitative consumer feedback. Electronic Commerce Research, 8(4), 217-234. https:// doi.org/10.1007/s10660-008-9022-0.

71. Tsao, W. C., \& Hsieh, M. T. (2015). eWOM persuasiveness: Do eWOM platforms and product type matter? Electronic Commerce Research, 15(4), 509-541. https://doi.org/10.1007/ s10660-015-9198-z.

72. Zhang, H., Rao, H., \& Feng, J. (2018). Product innovation based on online review data mining: A case study of Huawei phones. Electronic Commerce Research, 18(1), 3-22. https://doi.org/10. 1007/s10660-017-9279-2.

73. Liu, Q., Zhang, X., Zhang, L., \& Zhao, Y. (2019). The interaction effects of information cascades, word of mouth and recommendation systems on online reading behavior: An empirical investigation. Electronic Commerce Research, 19(3), 521-547. https://doi.org/10.1007/s10660-018-9312-0.

74. Chen, R., \& Xu, W. (2017). The determinants of online customer ratings: a combined domain ontology and topic text analytics approach. Electronic Commerce Research, 17(1), 31-50. https:// doi.org/10.1007/s10660-016-9243-6.

75. Narayanasamy, K., Rasiah, D., \& Tan, T. M. (2011). The adoption and concerns of e-finance in Malaysia. Electronic Commerce Research, 11(4), 383-400. https://doi.org/10.1007/ s10660-011-9081-5.

76. Dumas, M., Aldred, L., Governatori, G., \& Ter Hofstede, A. H. M. (2005). Probabilistic automated bidding in multiple auctions. Electronic Commerce Research, 5(1), 25-49. https://doi.org/10. 1023/B:ELEC.0000045972.75533.90.

77 Marinč, M. (2013). Banks and information technology: Marketability vs. relationships. Electronic Commerce Research, 13(1), 71-101. https://doi.org/10.1007/s10660-013-9107-2.

78. Maillé, P., Markakis, E., Naldi, M., Stamoulis, G. D., \& Tuffin, B. (2012). Sponsored search auctions: An overview of research with emphasis on game theoretic aspects. Electronic Commerce Research, 12(3), 265-300. https://doi.org/10.1007/s10660-012-9094-8.

79. Maillé, P., \& Tuffin, B. (2018). Auctions for online ad space among advertisers sensitive to both views and clicks. Electronic Commerce Research, 18(3), 485-506. https://doi.org/10.1007/ s10660-017-9267-6.

80. Håvaldsrud, T. V., Ligaarden, O. S., Myrseth, P., Refsdal, A., Stølen, K., \& Ølnes, J. (2010). Experiences from using a UML-based method for trust analysis in an industrial project on electronic procurement. Electronic Commerce Research, 10(3-4), 441-467. https://doi.org/10.1007/ s10660-010-9063-z. 
81. Dráb, R., Štofa, T., \& Delina, R. (2020). Analysis of the efficiency of electronic reverse auction settings: Big data evidence. Electronic Commerce Research (in press). https://doi.org/10.1007/ s10660-020-09433-0.

82. Bei, L. T., \& Chen, M. Y. (2015). The effects of hedonic and utilitarian bidding values on e-auction behavior. Electronic Commerce Research, 15(4), 483-507. https://doi.org/10.1007/ s10660-015-9197-0.

83. Huang, T. L., \& Liao, S. (2015). A model of acceptance of augmented-reality interactive technology: The moderating role of cognitive innovativeness. Electronic Commerce Research, 15(2), 269-295. https://doi.org/10.1007/s10660-014-9163-2.

84. Hsieh, J. K., Hsieh, Y. C., \& Tang, Y. C. (2012). Exploring the disseminating behaviors of eWOM marketing: Persuasion in online video. Electronic Commerce Research, 12(2), 201-224. https://doi.org/10.1007/s10660-012-9091-y.

85. Zhang, L., Luo, M., \& Boncella, R. J. (2020). Product information diffusion in a social network. Electronic Commerce Research, 20(1), 3-19. https://doi.org/10.1007/s10660-018-9316-9.

86. Zhanikeev, M. (2015). How variable bitrate video formats can help P2P streaming boost its reliability and scale. Electronic Commerce Research, 15(1), 25-47. https://doi.org/10.1007/ s10660-015-9175-6.

87. Cheng, X., Gu, Y., \& Mou, J. (2020). Interpersonal relationship building in social commerce communities: Considering both swift guanxi and relationship commitment. Electronic Commerce Research, 20(1), 53-80. https://doi.org/10.1007/s10660-019-09375-2.

88. Chu, X., Liu, Y., Chen, X., Ding, Z., \& Tao, S. (2020). What motivates consumer to engage in microblogs? The roles of brand post characteristics and brand prestige. Electronic Commerce Research (in press). https://doi.org/10.1007/s10660-020-09435-y.

89. Zhou, T. (2013). An empirical examination of user adoption of location-based services. Electronic Commerce Research, 13(1), 25-39. https://doi.org/10.1007/s10660-013-9106-3.

90. Chen, Q., Chen, H. M., \& Kazman, R. (2007). Investigating antecedents of technology acceptance of initial ECRM users beyond generation X and the role of self-construal. Electronic Commerce Research, 7(3-4), 315-339. https://doi.org/10.1007/s10660-007-9009-2.

91. Royo, S., \& Yetano, A. (2015). "Crowdsourcing" as a tool for e-participation: Two experiences regarding $\mathrm{CO}_{2}$ emissions at municipal level. Electronic Commerce Research, 15(3), 323-348. https://doi.org/10.1007/s10660-015-9183-6.

92. Chen, D., Li, X., \& Lai, F. (2017). Gender discrimination in online peer-to-peer credit lending: Evidence from a lending platform in China. Electronic Commerce Research, 17(4), 553-583. https://doi.org/10.1007/s10660-016-9247-2.

93. Yu, C. H., \& Lin, S. J. (2013). Fuzzy rule optimization for online auction frauds detection based on genetic algorithm. Electronic Commerce Research, 13(2), 169-182. https://doi.org/10.1007/ s10660-013-9113-4.

94. Yan, Y., Lv, Z., \& Hu, B. (2018). Building investor trust in the P2P lending platform with a focus on Chinese P2P lending platforms. Electronic Commerce Research, 18(2), 203-224. https://doi.org/10.1007/s10660-017-9255-x.

95. Guo, Y., \& Barnes, S. (2009). Virtual item purchase behavior in virtual worlds: An exploratory investigation. Electronic Commerce Research, 9(1-2), 77-96. https://doi.org/10.1007/ s10660-009-9032-6.

96. Bourlakis, M., Papagiannidis, S., \& Li, F. (2009). Retail spatial evolution: Paving the way from traditional to metaverse retailing. Electronic Commerce Research, 9(1-2), 135-148. https://doi. org/10.1007/s10660-009-9030-8.

97. MacInnes, I. (2006). Property rights, legal issues, and business models in virtual world communities. Electronic Commerce Research, 6(1), 39-56. https://doi.org/10.1007/s10660-006-5987-8.

98. Cagnina, M. R., \& Poian, M. (2009). Beyond e-business models: The road to virtual worlds. Electronic Commerce Research, 9(1-2), 49-75. https://doi.org/10.1007/s10660-009-9027-3.

99. Scarle, S., Arnab, S., Dunwell, I., Petridis, P., Protopsaltis, A., \& de Freitas, S. (2012). E-commerce transactions in a virtual environment: Virtual transactions. Electronic Commerce Research, 12(3), 379-407. https://doi.org/10.1007/s10660-012-9098-4.

100. Hanafizadeh, P., \& Khedmatgozar, H. R. (2012). The mediating role of the dimensions of the perceived risk in the effect of customers' awareness on the adoption of Internet banking in Iran. Electronic Commerce Research, 12(2), 151-175. https://doi.org/10.1007/s10660-012-9090-z. 
101. Valvi, A. C., \& Fragkos, K. C. (2012). Critical review of the e-loyalty literature: A purchasecentred framework. Electronic Commerce Research, 12(3), 331-378. https://doi.org/10.1007/ s10660-012-9097-5.

102. Aloudat, A., \& Michael, K. (2011). Toward the regulation of ubiquitous mobile government: A case study on location-based emergency services in Australia. Electronic Commerce Research, 11(1), 31-74. https://doi.org/10.1007/s10660-010-9070-0.

103. Tsai, H. T., Chien, J. L., \& Tsai, M. T. (2014). The influences of system usability and user satisfaction on continued Internet banking services usage intention: Empirical evidence from Taiwan. Electronic Commerce Research, 14(2), 137-169. https://doi.org/10.1007/s10660-014-9136-5.

104. Li, H., Aham-Anyanwu, N., Tevrizci, C., \& Luo, X. (2015). The interplay between value and service quality experience: E-loyalty development process through the eTailQ scale and value perception. Electronic Commerce Research, 15(4), 585-615. https://doi.org/10.1007/s10660-015-9202-7.

105. Khedmatgozar, H. R., \& Shahnazi, A. (2018). The role of dimensions of perceived risk in adoption of corporate internet banking by customers in Iran. Electronic Commerce Research, 18(2), 389-412. https://doi.org/10.1007/s10660-017-9253-z.

106. Zhou, R., Wang, X., Shi, Y., Zhang, R., Zhang, L., \& Guo, H. (2019). Measuring e-service quality and its importance to customer satisfaction and loyalty: an empirical study in a telecom setting. Electronic Commerce Research, 19(3), 477-499. https://doi.org/10.1007/s10660-018-9301-3.

107. Kim, J. B. (2012). An empirical study on consumer first purchase intention in online shopping: Integrating initial trust and TAM. Electronic Commerce Research, 12(2), 125-150. https://doi.org/ 10.1007/s10660-012-9089-5.

108. Gregg, D. G., \& Walczak, S. (2010). The relationship between website quality, trust and price premiums at online auctions. Electronic Commerce Research, 10(1), 1-25. https://doi.org/10.1007/ s10660-010-9044-2.

109. Taylor, D. G., Davis, D. F., \& Jillapalli, R. (2009). Privacy concern and online personalization: The moderating effects of information control and compensation. Electronic Commerce Research, 9(3), 203-223. https://doi.org/10.1007/s10660-009-9036-2.

110. Castañeda, J. A., \& Montoro, F. J. (2007). The effect of Internet general privacy concern on customer behavior. Electronic Commerce Research, 7(2), 117-141. https://doi.org/10.1007/ s10660-007-9000-y.

111. Chen, M. Y., \& Teng, C. I. (2013). A comprehensive model of the effects of online store image on purchase intention in an e-commerce environment. Electronic Commerce Research, 13(1), 1-23. https://doi.org/10.1007/s10660-013-9104-5.

112. Goel, L., \& Prokopec, S. (2009). If you build it will they come? An empirical investigation of consumer perceptions and strategy in virtual worlds. Electronic Commerce Research, 9(1-2), 115134. https://doi.org/10.1007/s10660-009-9031-7112.

113. Ninia, J. (2020). The impact of e-commerce: China versus the United States. Ithaca, New York: Cornell University.

114. IBM Research. (2020). Our labs. IBM. Available at https://www.research.ibm.com/labs/

115. Klein, J. T., \& Falk-Krzesinski, H. J. (2017). Interdisciplinary and collaborative work: Framing promotion and tenure practices and policies. Research Policy, 46(6), 1055-1061. https://doi.org/10. 1016/j.respol.2017.03.001.

116. Lim, W. M. (2019). To what degree is the fourth industrial revolution an opportunity or a threat for the ASEAN community and region? Modern Applied Science, 13(9), 105-106. https://doi.org/10. 5539/mas.v13n9p105.

117. Wijaya, D. R., Paramita, N. L. P. S. P., Uluwiyah, A., Rheza, M., Zahara, A., \& Puspita, D. R. (2021). Estimating city-level poverty rate based on e-commerce data with machine learning. Electronic Commerce Research. https://doi.org/10.1007/s10660-020-09424-.

118. Lim, W. M. (2020). Challenger marketing. Industrial Marketing Management, 84, 342-345. https:// doi.org/10.1016/j.indmarman.2019.08.009.

119. Lim, W. M. (2020). In defense of challenger marketing. Journal of Business-to-Business Marketing, 27(4), 397-406. https://doi.org/10.1080/1051712X.2020.1831214.

120. Lim, W. M. (2020). The sharing economy: A marketing perspective. Australasian Marketing Journal, 28(3), 4-13. https://doi.org/10.1016/j.ausmj.2020.06.007.

121. Lim, W. M. (2016). Understanding the selfie phenomenon: Current insights and future research directions. European Journal of Marketing, 50(9/10), 1773-1788. https://doi.org/10.1108/ EJM-07-2015-0484. 
122. Lim, W. M. (2018). Demystifying neuromarketing. Journal of Business Research, 91, $205-220$. https://doi.org/10.1016/j.jbusres.2018.05.036.

123. Lim, W. M. (2018). Dialectic antidotes to critics of the technology acceptance model: Conceptual, methodological, and replication treatments for behavioural modelling in technology-mediated environments. Australasian Journal of Information Systems. https://doi.org/10.3127/ajis.v22i0.1651.

124. Lim, W. M. (2018). What will business-to-business marketers learn from neuro-marketing? Insights for business marketing practice. Journal of Business-to-Business Marketing, 25(3), 251259. https://doi.org/10.1080/1051712X.2018.1488915.

125. Lim, W. M., Ahmed, P. K., \& Ali, M. Y. (2019). Data and resource maximization in business-tobusiness marketing experiments: Methodological insights from data partitioning. Industrial Marketing Management, 76, 136-143. https://doi.org/10.1016/j.indmarman.2018.08.007.

126. Lim, W. M., Yap, S. F., \& Makkar, M. (2021). Home sharing in marketing and tourism at a tipping point: What do we know, how do we know, and where should we be heading? Journal of Business Research, 122, 534-566. https://doi.org/10.1108/EJM-07-2015-0484. 